\title{
Secondary Metabolites Governing Microbiome Interaction of Staphylococcal Pathogens and Commensals
}

\author{
Benjamin O. Torres Salazar ${ }^{a, b}$, c Simon Heilbronner ${ }^{a, b, c} \quad$ Andreas Peschel $^{a, b}, c$ \\ Bernhard Krismer ${ }^{a}$, b, c \\ aDepartment of Infection Biology, Interfaculty Institute of Microbiology and Infection Medicine, University of \\ Tübingen, Tübingen, Germany; ${ }^{\mathrm{b}}$ Cluster of Excellence EXC 2124 Controlling Microbes to Fight Infections, \\ Tübingen, Germany; ${ }^{\circ}$ German Center for Infection Research (DZIF), partner site Tübingen, Tübingen, Germany
}

\section{Keywords}

Staphylococcus · Microbiome active compounds .

Bacteriocins · Quorum sensing · Metallophores

\begin{abstract}
Various Staphylococcus species colonize skin and upper airways of warm-blooded animals. They compete successfully with many other microorganisms under the hostile and nutrient-poor conditions of these habitats using mechanisms that we are only beginning to appreciate. Small-molecule mediators, whose biosynthesis requires complex enzymatic cascades, so-called secondary metabolites, have emerged as crucial components of staphylococcal microbiome interactions. Such mediators belong to a large variety of compound classes and several of them have attractive properties for future drug development. They include, for instance, bacteriocins such as lanthipeptides, thiopeptides, and fibupeptides that inhibit bacterial competitor species; signaling molecules such as thiolactone peptides that induce or inhibit sensory cascades in other bacteria; or metallophores such as staphyloferrins and staphylopine that scavenge scant transi-
\end{abstract}

karger@karger.com www.karger.com/mip

Karger!"

BOPEN ACCESS
(C) 2021 The Author(s)

Published by S. Karger AG, Basel

This is an Open Access article licensed under the Creative Commons Attribution-NonCommercial-4.0 International License (CC BY-NC) (http://www.karger.com/Services/OpenAccessLicense), applicable to the online version of the article only. Usage and distribution for commercial purposes requires written permission. tion metal ions. For some secondary metabolites such as the aureusimines, the exact function remains to be elucidated. How secondary metabolites shape the fitness of Staphylococcus species in the complex context of other microbial and host defense factors remains a challenging field of future research. A detailed understanding will help to harness staphylococcal secondary metabolites for excluding the pathogenic species Staphylococcus aureus from the nasal microbiomes of at-risk patients, and it will be instrumental for the development of advanced anti-infective interventions.

$$
\begin{aligned}
& \text { (c) } 2021 \text { The Author(s) } \\
& \text { Published by S. Karger AG, Basel }
\end{aligned}
$$

\section{Introduction}

The genus Staphylococcus comprises dozens of species that are frequent colonizers of epithelial surfaces such as the skin or nasal cavities of humans and animals [Grice and Segre, 2011; Coates et al., 2014]. The most prominent and most extensively investigated species is the coagulase-positive Staphylococcus aureus, an opportunistic human pathogen that can switch from a commensal to a 
pathogenic lifestyle, thereby causing a variety of infections [Lee et al., 2018]. In contrast, the vast majority of staphylococci belongs to coagulase-negative Staphylococcus species including for instance the species Staphylococcus epidermidis and Staphylococcus hominis, which are considered to be mostly commensals and less harmful than $S$. aureus, although they occasionally also cause infections [Becker et al., 2014]. With their high prevalence on skin and the epithelia of the nose, staphylococci are regarded as key members of the human microbiome [Coates et al., 2014].

Compared to the microbiome of the gastrointestinal tract, the microbiomes of the human skin and nose has only moderate biodiversity with a considerable overlap in occurring species. The nose, for example, is home to members of the genera Cutibacterium, Corynebacterium, Moraxella, and Dolosigranulum forming communities with staphylococci [Krismer et al., 2017; Rawls and Ellis, 2019]. They are considered to support the first line of host defense because some commensals can inhibit colonization and infection by more pathogenic species such as $S$. aureus [Coates et al., 2014]. We have only begun to understand by which mechanisms these beneficial species can confer pathogen colonization resistance. The composition of bacterial communities is influenced by host-bacteria interactions (reviewed in more detail elsewhere [Parlet et al., 2019; Flowers and Grice, 2020; Otto, 2020]) and by interbacterial interactions. Such bacterial interactions involve the exchange of nutrients and molecules that induce or inhibit specific functions in target bacteria, so called secondary metabolites. The latter are highly diverse organic compounds that are often not essential for bacterial primary metabolism but may provide beneficial traits to the producing bacteria [Braga et al., 2016]. Secondary metabolites exert a wide range of bioactivities, which can be beneficial, detrimental, or even fatal for close-by bacterial community members. The production of such secondary metabolites can be an important strategy for bacteria to ensure their own survival and affect that of other bacteria.

Owing to recent advances in genome-wide sequencing techniques, we begin to understand the role of staphylococci within bacterial skin and nasal communities and to unravel the nature of their interactions. Many of these attempts were focused on $S$. aureus and its interaction with the human microbiome, to find new strategies for interfering with $S$. aureus colonization (to establish colonization resistance) [Botelho-Nevers et al., 2017; Otto, 2020]. Three types of secondary metabolites have been found to be particularly important. The first includes bacteriocins, antimicrobial compounds that inhibit the growth of other bacteria [Cotter et al., 2005a]. Bacteriocins strongly impact the competition of bacteria for colonization sites and/or nutrients [Krismer et al., 2017]. Bacteriocins have been defined as ribosomally synthesized peptides [Arnison et al., 2013]. However, to cover all known antimicrobial compounds, the term bacteriocin is used in a broader sense to include all antimicrobial substances used by staphylococci in microbiome competition, independent of their biosynthetic pathway.

Several previous studies have demonstrated that nasal and skin staphylococcal species frequently produce antimicrobial compounds that are active against other inhabitants of the same niche, suggesting, that their production may be advantageous for the producers' establishment and survival on the human epithelia [Janek et al., 2016; O'Sullivan et al., 2018]. Nakatsuji et al. observed that $S$. aureus occurrence on skin of atopic dermatitis patients is significantly reduced in the presence of staphylococcal commensals that produce bacteriocins of the lantibiotics type [Nakatsuji et al., 2017; Nakatsuji et al., 2021]. Of note, also non-staphylococcal species such as Cutibacterium acnes produce antimicrobials that inhibit staphylococci including S. epidermidis [Christensen et al., 2016; Claesen et al., 2020].

The second type covers molecules that interfere with bacterial signaling pathways, in particular the staphylococcal accessory gene regulator (agr), a quorum sensing (QS) system. This system is present in all staphylococci. It uses thiolactone/lactone containing autoinducing peptides (AIPs) for cell density-dependent signaling [Le and Otto, 2015]. They exist as members of different structural subgroups, and several studies have demonstrated that AIPs can cross-inhibit signaling of staphylococci belonging to other subgroups, a phenomenon referred to as quorum quenching [Ji et al., 1997; Thoendel et al., 2011; Otto, 2020].

Metallophores have almost exclusively been investigated for their importance during infections, but they may play an important role for bacterial interactions in the microbiome. These low-molecular-weight molecules are produced by bacteria during limited availability of essential transition metal ions, such as iron or zinc, in order to scavenge them from the environment and to deliver them back to the cells [Kramer et al., 2020]. The human nasal epithelium represents an environment with limited availability of essential metals such as iron [Krismer et al., 2017] suggesting that metallophores may be also involved in staphylococcal persistence in human microbiomes. 
As diverse as bacterial interactions are, as manifold are the substance classes and biosynthetic pathways of bacterial interactions shaping secondary compounds, ranging from ribosomally synthesized and post-translationally modified peptides (RiPPs) to non-ribosomally synthesized peptides (NRPs) and non-peptide molecules. In this review, we outline the different classes of the hitherto identified community-active secondary compounds produced by staphylococcal species, with emphasis on the biosynthetic pathways. Secondary metabolites from the group of unmodified peptides (class-II bacteriocins) and the small-peptide family of phenol-soluble modulins (PSMs) are not covered by this review, despite their presumably huge impact on the microbiome.

\section{Ribosomally Synthesized and Post-Translationally Modified Peptides}

The term "RiPPs" was first introduced in a review published by a discussion group under the leadership of Wilfred van der Donk as a recommendation to summarize the plethora of peptides that are ribosomally synthesized and get subsequently modified by enzymes that are encoded in diverse biosynthetic gene clusters (BGCs) [Arnison et al., 2013; Montalban-Lopez et al., 2021]. RiPPs are relatively small molecules with a size below $10 \mathrm{kDa}$, representing a superfamily of natural products with diverse structural features and biological functions [Arnison et al., 2013].

The peptide backbones of RiPPs are encoded by structural genes leading to precursor peptides with lengths of 20-110 amino acids. The precursor peptide is composed of different segments, of which the so-called core peptide will eventually be transformed into the mature bioactive product [Arnison et al., 2013]. Most precursor peptides of RiPPs possess a leader peptide attached to the core peptide at the $\mathrm{N}$-terminus, which will be removed upon RiPP maturation [Oman and van der Donk, 2010]. In some cases, the leader peptide is attached to the C-terminus of the core peptide and can contain recognition sequences, which are important during maturation of the peptide for excision and cyclization [Arnison et al., 2013].

During RiPP biosynthesis, the leader peptide is used for recognition of the unprocessed precursor peptide by post-translational modification (PTM) enzymes and by export proteins [Oman and van der Donk, 2010]. Those enzymes gradually modify the unmodified core peptide to yield the modified core peptide (MCP) [Arnison et al., 2013]. PTMs of RiPPs can be highly diverse and include, for instance, dehydration, phosphorylation, cyclization, and oxidation reactions. Further downstream of the modification process, the leader peptide is finally removed from the MCP by proteolytic cleavage, resulting in the release of the mature bioactive RiPP [Arnison et al., 2013].

In staphylococci, the currently known RiPPs are bacteriocins or signaling molecules, belonging to the classes of lanthipeptides, sactipeptides, thiopeptides, or thiolactones, which will be discussed in this section (see also Table 1).

\section{Lanthipeptides}

Lanthipeptides are RiPPs containing the unusual amino acids lanthionine (Lan) or 3-methyllanthionine (MeLan) and, sometimes, the dehydrated amino acids didehydroalanine (Dha) or didehydrobutyrine (Dhb) [Schnell et al., 1988; Guder et al., 2000]. Lan and MeLan result from the condensation of a Dha or Dhb with a Cys leading to a thioether linkage that connects their $\beta$-carbons [Guder et al., 2000]. They are typically formed by PTM enzymes with dehydratase and cyclase activities from Ser or Thr, which are in the first step dehydrated to Dha or Dhb, respectively, and, in a second step, linked to the thiol group of intramolecular Cys residues resulting in Lan or MeLan formation, respectively [Guder et al., 2000].

Lanthipeptides with antimicrobial activity are called lantibiotics and, according to Knerr and van der Donk [Knerr and van der Donk, 2012], can be further divided into class I-IV lantibiotics, depending on the enzymes involved in PTM of the lantibiotic. In class-I lantibiotics, two separate enzymes mediate dehydration and cyclization, the dehydratase LanB and the cyclase LanC, respectively, while in class-II (LanM), class-III (LanKC), and class-IV (LanL), only one enzyme accomplishes lanthionine formation [Knerr and van der Donk, 2012].

The target sites of lantibiotics are typically surface structures of Gram-positive bacteria such as lipid I and II, which are precursors for peptidoglycan biosynthesis [Reisinger et al., 1980; Brötz et al., 1998; Breukink et al., 1999], as well as lipid III and IV, precursors for wall teichoic acid biosynthesis [Müller et al., 2012]. For epidermin/gallidermin, two of the lantibiotics produced by staphylococci, it has been demonstrated that upon binding to lipid II, the incorporation of lipid II via the transpeptidase/trans-glycosylase into the growing peptidoglycan network is blocked, thus resulting in the death of target bacterial cells [Götz et al., 2014]. Furthermore, pore formation with a consequent dissipation of the mem- 
Table 1. Bacteriocins identified from Staphylococcus species

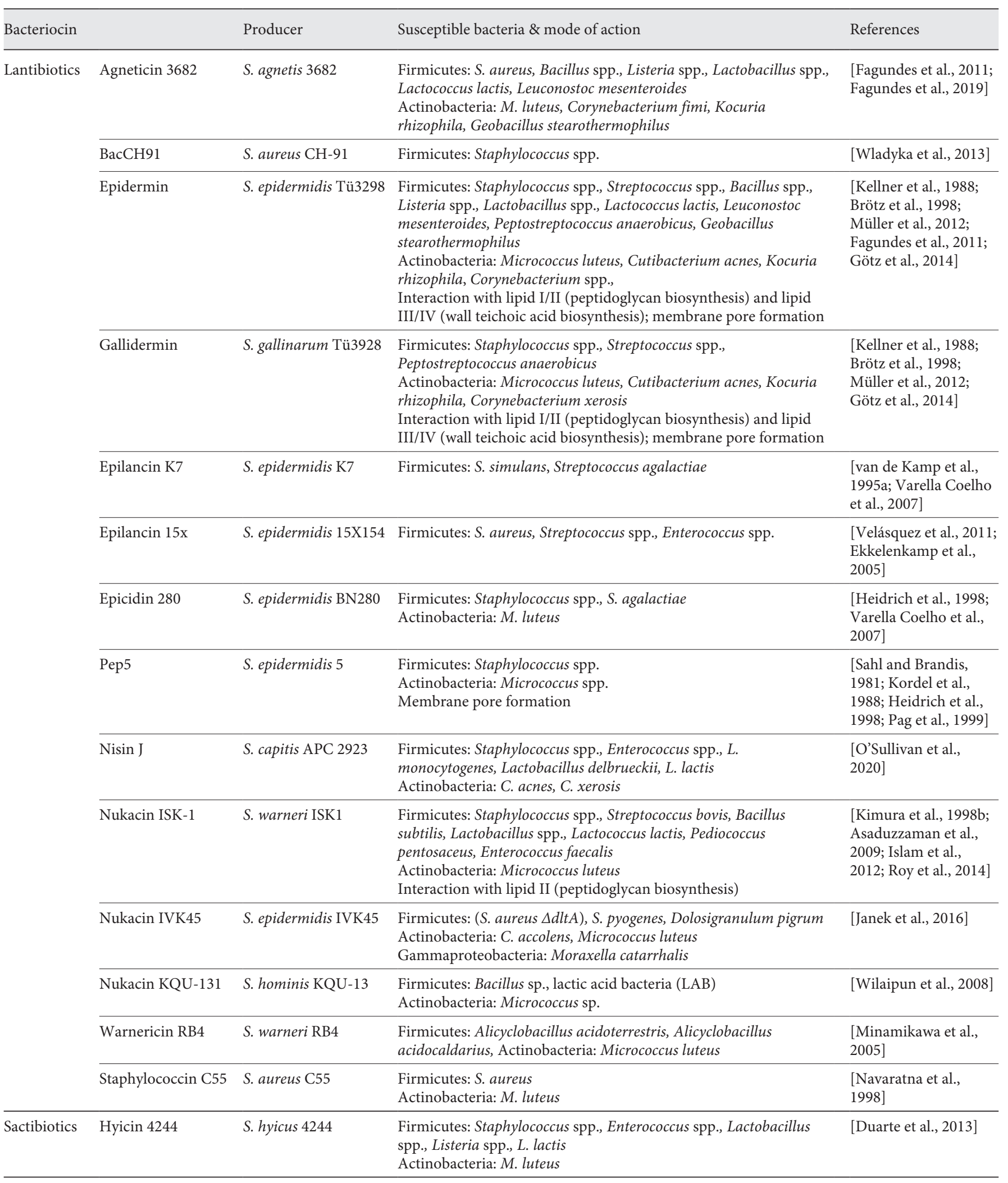


Table 1 (continued)

\begin{tabular}{|c|c|c|c|}
\hline Thiopeptides Micrococcin P1 & $\begin{array}{l}\text { S. equorum WS } 2733 / S \text {. } \\
\text { hominis S34-1 }\end{array}$ & $\begin{array}{l}\text { Firmicutes: Staphylococcus spp., Enterococcus spp., Listeria spp., } \\
\text { Lactobacillus sp., Bacillus cereus, Clostridium perfringens } \\
\text { Actinobacteria: Corynebacterium sp., Micrococcus sp., } \\
\text { Brevibacterium sp., Arthrobacter sp., Microbacterium sp. } \\
\text { Interaction with complex formed between L11 binding domain of } \\
50 \text { S ribosomal subunit and } 23 \text { S ribosomal RNA, thereby inhibiting } \\
\text { peptide chain elongation }\end{array}$ & $\begin{array}{l}\text { [Cundliffe and } \\
\text { Thompson, 1981; } \\
\text { Carnio et al., 2000] }\end{array}$ \\
\hline
\end{tabular}

brane potential is associated with killing. However, this seems to depend on the thickness of the membrane of the target cell and the length of lantibiotics [Breukink et al., 1999; Bonelli et al., 2006].

In general, the generic locus symbol lan is used to designate the entire group of lantibiotic gene clusters, which have, depending on the lantibiotic, more specific genotypic denotations, for example, nuk for nukacin ISK-1 or $g d m$ for gallidermin [Arnison et al., 2013]. Further, the gene clusters typically contain genes encoding the precursor peptide $(\operatorname{lan} A)$, PTM enzymes $(\operatorname{lan} B, \operatorname{lan} C$, lan $M$, $\operatorname{lan} L$, etc.), an exporter ( $\operatorname{lan} T)$, and extracellular protease $(\operatorname{lan} P)$ for the transport of the MCP and proteolytic cleavage of the leader peptide, and proteins for immunity (lanI, lan $H$, lanFEG) that protect the producer from its own product [Siezen et al., 1996; Bierbaum and Sahl, 2009]. In some staphylococcal class-I lantibiotics, additional PTM enzymes such as LanD [Schnell et al., 1992; Kupke et al., 1994] and LanO [Velásquez et al., 2011] have been identified that are associated with additional PTMs, for example, for epidermin or epilancin 15X, respectively.

Epidermin and its natural derivative gallidermin are among the best described staphylococcal class-I lantibiotics and were originally discovered in S. epidermidis Tü3298 and Staphylococcus gallinarum Tü3928, respectively [Allgaier H, 1985; Kellner et al., 1988]. The biosynthesis of epidermin and gallidermin is nearly identical, and the core peptides only differ by one amino acid (Leu6Ile in gallidermin) [Kellner et al., 1988]. Both BGCs consist of 11 genes and are, in the case of epidermin, organized as epiGEFHTABCDQP locus, with epiQ [Peschel et al., 1993] and epiD [Schnell et al., 1992; Kupke et al., 1994] encoding for a regulator and an additional PTM enzyme, respectively.
The ribosomally synthesized precursor peptide contains the 22-aa core peptide that will become the mature lanthipeptide. The formation of lanthionine and methyllanthionine is mediated via $\mathrm{EpiB}$ and EpiC, resulting in the generation of three thioether ring structures in the epidermin core peptide segment (Fig. 1) [Götz et al., 2014]. One special structural feature of epidermin and gallidermin is the fourth thioether ring at the $\mathrm{C}$-terminus, a S-((Z)-2-aminovinyl)-D-Cys (AviCys) residue, generated by the PTM enzyme EpiD/GdmD, a flavoprotein that binds the coenzyme flavin mononucleotide (FMN) [Kupke et al., 1992; Kupke and Götz, 1997; Götz et al., 2014]. The resulting MCP is then secreted via the ABC transporter EpiHT in a sec-independent way and is extracellularly cleaved by the leader peptidase EpiP to form the mature and active gallidermin [Geissler et al., 1996; Götz et al., 2014].

Over the years, further staphylococcal class-I lantibiotics have been identified that are variants of or closely related to epidermin: 1V,6L-epidermin from S. epidermidis V1 and V301 [Bierbaum et al., 1996], staphylococcin $\mathrm{T}$ (identical to gallidermin) from Staphylococcus cohnii T [Furmanek et al., 1999], staphylococcin Au-26/Bsa/aureodermin [Scott et al., 1992; Daly et al., 2010; Joo et al., 2011] and BacCH91 [Wladyka et al., 2013] from S. aure$u s$, and agneticin 3682 (formerly hyicin 3682) isolated from Staphylococcus agnetis (formerly Staphylococcus hyicus) [Fagundes et al., 2011; Fagundes et al., 2019].

Another member of staphylococcal class-I lantibiotics is epilancin 15X, originating from S. epidermidis 15X154 and encoded by the BGC elxOTAPBCI [Ekkelenkamp et al., 2005; Velásquez et al., 2011]. A special feature of epilancin $15 \mathrm{X}$ is an N-terminal lactate residue (Fig. 1). Upon biosynthesis of the precursor peptide and Lan/MeLan 


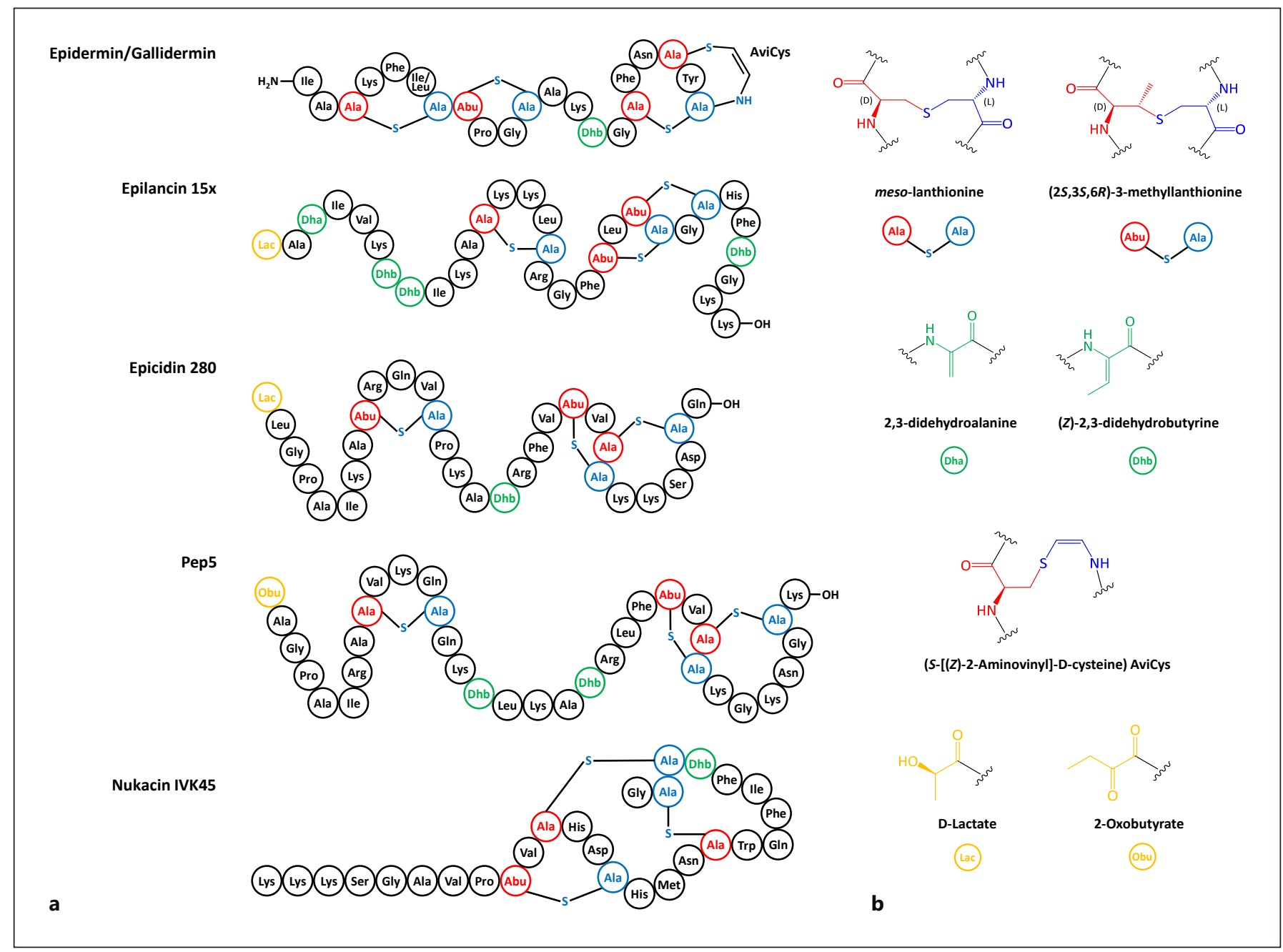

Fig. 1. a Amino acid sequence and ring topologies/structures of staphylococcal lanthipeptides. Red: alanine (Ala) and aminobutyric acid (Abu) derived from serine and threonine; blue: Ala derived from cysteine; green: 2,3-didehydroalanine (Dha) and (Z)-2,3-didehydrobutyrine (Dhb) derived from serine and threo-

formation, the leader peptide is proteolytically removed by ElxP, a presumed intracellular protease that leaves the 31-aa core peptide with an N-terminal Dha [Velásquez et al., 2011]. Due to instability, the Dha undergoes spontaneous hydrolysis to form a pyruvate residue, which is then reduced by the NADPH-dependent PTM enzyme ElxO, resulting in an $\mathrm{N}$-terminal lactate residue [Velásquez et al., 2011]. The mature peptide is most likely secreted by ElxT, a putative $\mathrm{ABC}$ exporter [Velásquez et al., 2011]. Like epilancin 15X, its natural derivative epilancin $\mathrm{K} 7$ also possesses an $\mathrm{N}$-terminal lactate residue [van de Kamp et al., 1995a; van de Kamp et al., 1995b]. However, to date, no LanO has been identified that could nine; yellow: D-lactate and 2-oxobutyrate derived from $\mathrm{N}$-terminal Dha or Dhb. b Chemical structures of lanthipeptide characteristic unnatural amino acids lanthionine, methyllanthionine, didehydroalanine and didehydrobutyrine and further chemical modifications. be responsible for this modification step in epilancin K7 [Heidrich et al., 1998; Velásquez et al., 2011]. Nevertheless, an elxO homolog could be found in the BGC eciOIAPBC of epicidin 280, a lantibiotic derived from $S$. epidermidis BN280 (Fig. 1) [Heidrich et al., 1998]. Here, the el $x O$ homolog eciO encodes a PTM enzyme EciO with putative oxidoreductase function. Most likely EciO catalyzes the conversion of the $\mathrm{N}$-terminal pyruvate to a lactate residue; however, experimental evidence for this is currently lacking [Heidrich et al., 1998; Repka et al., 2017].

Closely related to epicidin 280 is Pep5, originally identified in S. epidermidis 5, which harbors the Pep 5 BGC 
pepTIAPBC [Ersfeld-Dressen et al., 1984; Weil et al., 1990; Meyer et al., 1995]. The BGC of Pep5 is organized in the same order as epicidin 280 BGC and the encoding proteins contain high levels of amino acid similarity [Heidrich et al., 1998; Bastos et al., 2009]. The precursor peptides of the two bacteriocins share $58.9 \%$ amino acid identity and both are synthesized with a 26 -aa leader peptide. However, the Pep5 core peptide consist of 34 aa, while that of epicidin 280 consists of only 30 aa [Bastos et al., 2009]. The mature peptide harbors an N-terminal oxobutyryl residue, which is formed by spontaneous deamination of the N-terminal Dhb (Fig. 1) [Kellner et al., 1989; Weil et al., 1990; Bierbaum et al., 1996]. In contrast to epicidin 280, the Pep5 BGC lacks a lanO gene and only the two PMT enzymes PepB/C are used to modify the Pep5 core peptide [Meyer et al., 1995]. Thus, Pep5 represents a class-I lantibiotic without any further enzymatic modification besides the formation of Lan/MeLan and Dha/Dhb. Apart from Pep5, there have been other lantibiotics isolated from staphylococci modified only by LanB and LanC, such as nisin J from Staphylococcus capitis [O'Sullivan et al., 2020].

A typical example for staphylococcal class-II lantibiotics is nukacin ISK-1, a 27-aa lantibiotic, originally isolated from Staphylococcus warneri ISK1, harboring the nukacin ISK-1 BGC nukAMTFEGH [Kimura et al., 1998a; Kimura et al., 1998b; Sashihara et al., 2000]. In contrast to the class-I lantibiotics described above, the formation of Lan and MeLan in nukacin ISK-1 is mediated by the single bi-functional enzyme LanM (NukM) [Aso et al., 2004; Shimafuji et al., 2015]. Whereas the C-terminal cyclase domain of LanM modification enzymes shares homologies to LanC enzymes, the N-terminal dehydratase domain of LanM bears no sequence similarities to LanB enzymes [Knerr and van der Donk, 2012]. These differences are also reflected by the distinct modes of dehydration of Ser and Thr, as dehydration mediated by LanM occurs via phosphorylation instead of glutamylation via LanB (reviewed in more detail elsewhere [Repka et al., 2017]). As for staphylococcal class-I lantibiotics, the leader peptide of NukA is removed after NukM catalyzed Lan/ MeLan formation, and the mature core peptide is released. However, both the cleavage of the MCP and the export of the resultant nukacin ISK-1 are mediated by only one enzyme, NukT, an ABC transporter maturation and secretion (AMS) protein [Nishie et al., 2009], which includes a peptidase domain.

Apart from S. warneri ISK-1, nukacin variants could be isolated from other staphylococcal species. Janek and colleagues identified the first $S$. epidermidis-derived nu- kacin-like bacteriocin produced by the human nasal isolate S. epidermidis IVK45, termed nukacin IVK45 (Fig. 1) [Janek et al., 2016]. The gene cluster of nukacin IVK45 shares high similarities to that of nukacin ISK-1 and nukacin KQU-131, another variant produced by $S$. hominis from fermented fish [Wilaipun et al., 2008; Janek et al., 2016]. The mature nukacin IVK45 differs from the other two nukacins by five and by six amino acids, respectively, and the leader peptide by another five amino acids [Janek et al., 2016]. Further examples of staphylococcal nukacinlike bacteriocins are nukacin 3299 (formerly designated simulancin 3299), a peptide produced by Staphylococcus simulans shown to be identical to nukacin ISK-1 [Ceotto et al., 2010], or warnericin RB4, a nukacin variant produced by S. warneri [Minamikawa et al., 2005].

A rather exotic class-II lantibiotic is staphylococcin C55, a two-component lantibiotic produced by S. aureus C55 [Navaratna et al., 1998]. Its BGC harbors two structural genes $s a c \alpha A$ and $\operatorname{sac} \beta A$, encoding C55 $\alpha$ and C55 $\beta$, respectively, the two lanM genes sacM1 and sacM2, an AMS protein encoding gene $s a c T$, and a gene coding for an additional modification enzyme, SacJ, a zinc and $\mathrm{NADPH}$-dependent LanJ $_{\mathrm{A}}$-type dehydrogenase [O'Connor et al., 2007; Repka et al., 2017]. The function of LanJ was first characterized for the biosynthesis of lacticin 3147 from Lactococcus lactis DPC3147, where it is thought to be responsible for the introduction of the amino acid D-Ala into the peptides [Cotter et al., 2005b]. In general, this modification step occurs after Dha formation by LanM, followed by a diastereoselective hydrogenation of Dha mediated by LanJ, resulting in the formation of D-Ala, thereby rendering Dha a substrate not only for Lan formation by LanM but also for D-Ala formation by LanJ [Cotter et al., 2005b]. The cleavage and transport of the two MCPs is most likely mediated by SacT, in the same way as LtnT in the lacticin 3147 biosynthesis process [Cotter et al., 2005b; O'Connor et al., 2007]. Interestingly, even though faint antimicrobial activity could be observed for the single peptides C55 $\alpha$ and C55 $\beta$, a combination of them at equimolar ratio is required to obtain full antimicrobial activity of staphylococcin C55 [Navaratna et al., 1998]. The genetic determinants of staphylococcin C55 could also be identified in S. aureus strain U0007 [Crupper et al., 1997].

Most recently, the BGC for another putative two-component lantibiotic was discovered in S. hominis APC 3824, exhibiting similarities to the BGC of haloduracin, a lantibiotic produced by Bacillus halodurans C-125 [Angelopoulou et al., 2020]. 


\section{Sactipeptides}

Sactipeptides are a class of RiPPs containing intramolecular thioether linkages between the thiol group of Cys and the $\alpha$-carbon of an acceptor amino acid [Arnison et al., 2013]. Such "sulfur-to- $\alpha$-carbon" condensations are generally mediated by radical S-adenosylmethionine (SAM) enzymes harboring [4Fe-4S] clusters [Flühe et al., 2012]. The general mechanism of thioether bond formation by the radical SAM enzyme has been described in more detail for subtilosin A, a sactipeptide derived from Bacillus subtilis [Flühe et al., 2012].

Sactipeptides with antimicrobial properties are called sactibiotics [Arnison et al., 2013]. Only a few studies have elucidated the mode of action of sactibiotics. Most sactipeptides have relatively high hydrophobic properties and tend to form hairpin structures due to their sulfur-to- $a-$ carbon linkages. Their hydrophobic residues are pointing to the outside, enabling an interaction with the membrane of the targeted organism, possibly resulting in some kind of membrane damage [Mathur et al., 2017].

Among staphylococci, only one sactibiotic has been described in more detail so far, hyicin 4244 (Table 1), which is produced by Staphylococcus hyicus, whose final structure has yet to be elucidated [Duarte et al., 2013; Duarte et al., 2018]. Its BGC is located on the chromosome and consists of eight genes (hyiSABCDEFG) with an organization resembling that of subtilosin A. The structural gene hycS encodes a 43 -aa precursor peptide with high identity (71\%) to the precursor peptide of subtilosin A (SboA). It harbors three thioether donor Cys residues (Cys12, Cys15, Cys21) and acceptor amino acids (Phe30, Phe39 and Thr36). The mature hyicin 4244 is assumed to be 35 -aa long and probably also undergoes macrocyclization to form a circular bacteriocin related to subtilosin A [Duarte et al., 2018].

The proteins encoded by the hyicin 4244 BGC also display high similarities (from $42 \%$ to $70 \%$ ) to the proteins of subtilosin A. Hence, they have most likely the same functions. In brief, HycA is the radical SAM enzyme that presumably introduces thioether linkages in $\mathrm{HycS}$, analogous to AlbA for subtilosin A, while $\mathrm{HycE}$ and $\mathrm{HycF}$ are predicted to be cytoplasmic proteases that are involved in the removal of the leader peptide and macrocyclization to generate the mature hyicin. Further genes encode the putative immunity factors $\mathrm{HycB}, \mathrm{HycC}$, and $\mathrm{HycD}$, whereas the latter two are presumably also involved in the transport of the mature peptide [Duarte et al., 2018].

Recently, four putative distinct sactipeptides were identified in S. epidermidis genomes, displaying only little sequence similarity to known sactibiotics $(<20.6 \%)$ [Angelopoulou et al., 2020]. Although the producers showed

Staphylococcus Secondary Metabolites antimicrobial activity against various bacteria, those sactibiotics were mostly investigated on a genetic level, and further research is required to confirm that the antimicrobial activity was caused by these putative sactibiotics.

\section{Thiopeptides}

Thiopeptides, or thiazolyl peptides, represent one of the most extensively modified RiPP class [Bagley et al., 2005; Wieland Brown et al., 2009]. They typically comprise a characteristic six-membered, nitrogenous heterocycle located at the center of the peptide, which functions as a scaffold for at least one peptide macrocycle and a tail. Both are featured by azole rings (oxazole, thiazole, or thiazoline) and dehydroamino acids (Dha/Dhb), which are derived from multistep modifications of Ser, Thr, and Cys [Bagley et al., 2005; Just-Baringo et al., 2014].

Thiopeptides can be classified into five series (a-e) according to their structure, depending on the substitution pattern and oxidation state of the nitrogenous heterocycle [Bagley et al., 2005]. They often exhibit antimicrobial activities against Gram-positive bacteria, and their modes of action are usually linked to the inhibition of protein biosynthesis. On one hand, this process can occur by binding to the GTPase-associated region of the ribosome/ L11 complex, thereby hindering elongation factors to bind, which results in ribosome stalling [Harms et al., 2008; Walter et al., 2012; Just-Baringo et al., 2014]. On the other hand, the peptide can bind to the elongation factor TU (EF-Tu), which prevents the formation of the EFTu-aminoacyl-tRNA complex [Heffron and Jurnak, 2000; Parmeggiani et al., 2006].

The first and yet only thiopeptide identified in the genus Staphylococcus is micrococcin P1 (MP1), originally isolated in 1948 from Micrococcus sp. and since then found twice, in Staphylococcus equorum WS 2733 and in S. hominis (Fig. 2, Table 1) [Su, 1948; Carnio et al., 2000; Liu et al., 2020]. As for the latter, the BGC for MP1 is located on a plasmid and shows high similarities to the MP1 BGC found in Macrococcus caseolyticus (formerly falsely classified as S. epidermidis) [Bennallack et al., 2014; Bennallack et al., 2016; Liu et al., 2020]. Using Bacillus subtilis for heterologous gene expression, eight PTM enzymes encoded by the tclIJKLMNPS BGC have been shown to be sufficient to produce MP1 [Bennallack et al., 2016]. The structural gene $t c l E$ encodes a 49 -aa MP1 precursor peptide of which the 14-aa at the C-terminus represent the core peptide with a high content of Ser, Thr, and Cys, which eventually is transformed into mature MP1 with two Dhb residues, six thiazole rings, and one central pyridine ring (Fig. 2). 


\section{a $\overline{\text { SCTTCVCTCS̄CCTT }}$}

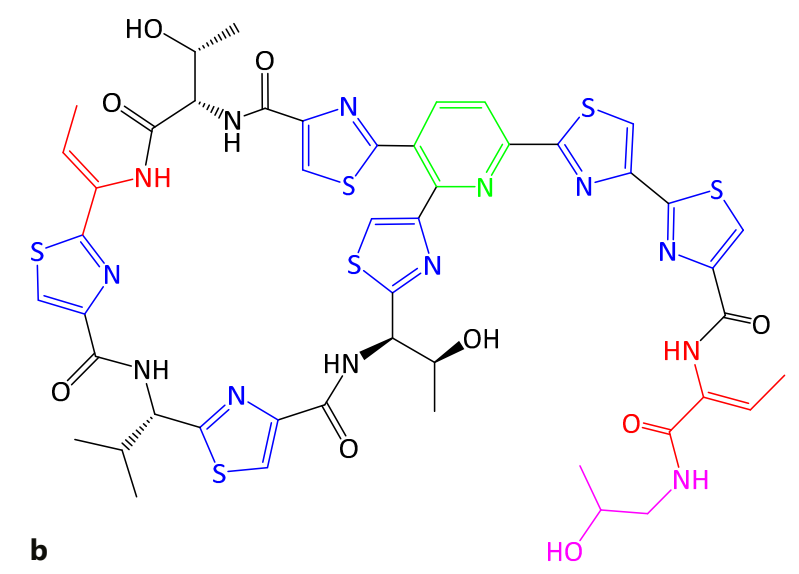

Fig. 2. a Amino acid sequence of micrococcin P1. Color code indicates posttranslational modifications. Red: dehydration; blue: thiazole formation; pink: dehydrogenation; green line: cyclization and pyridine formation. b Chemical structure of micrococcin P1.

Bewley et al. proposed a biosynthetic pathway for MP1 based on homology comparisons with other well-studied thiopeptides (thiocillin and thiomuracin) and supportive experimental data [Bewley et al., 2016]. In brief: during MP1 biosynthesis, the formation of thiazole rings is catalyzed by TclI (precursor peptide recognition), TclJ (a thiazole/oxazole-modified microcin family cyclodehydratase) and TclN (FMN-binding McbC-type dehydrogenase) in an ATP- and FMN-dependent manner [Bewley et al., 2016]. The alcohol residue at the C-terminal tail of MP1 is generated by the two predicted short-chain dehydrogenases TclP and TclS, with TclP responsible for the formation of a ketone residue that is later reduced by TclS to an alcohol. The two enzymes TclK and TclL catalyze the dehydration of Ser and Thr to Dha and Dhb, respectively, and the multifunctional TclM catalyzes the formation of the central pyridine ring, the peptide macrocyclization and leader peptide elimination. Further genes, not associated with MP1 PTM but encoded within the same cluster, are $t c l Q, t c l U$, and orf18, encoding a MP1-insensitive ribosomal protein L11 homolog conferring immunity, a putative transcriptional regulator, and a putative protein of unknown function, respectively [Bennallack et al., 2016].

\section{Thiolactones/Thiolactone-Containing Peptides}

Thiolactones are heterocyclic rings of different sizes that contain a sulfur atom adjacent to a carbonyl group. In virtually all Staphylococcus species, thiolactones are structural elements of AIPs that are involved in the accessory gene regulation (agr) QS system, allowing population density/environment-dependent gene regulation through cell-cell communication [Ji et al., 1995; Thoendel et al., 2011; Le and Otto, 2015]. In brief, the agr locus consists of two transcriptional units, RNAII and RNAIII, of which the RNAII locus contains the four genes $\operatorname{agr} B$, $\operatorname{agr} C$, $\operatorname{agr} D$, and $\operatorname{agr} A$ involved in QS [Le and Otto, 2015]. AgrC and AgrA represent a two-component signal transduction system. AgrC is the transmembrane histidine kinase sensor that gets auto-phosphorylated upon AIP binding [Lina et al., 1998]. Subsequently, it transfers the phosphate group to the associated response regulator AgrA, which then activates the $\mathrm{P} 2 / \mathrm{P} 3$ promotor regions of RNAII/RNAIII, respectively, resulting in an auto-feedback regulation of agrBDCA and transcription/translation of RNAIII that regulates expression of agr target genes [Novick et al., 1995; Koenig et al., 2004; Queck et al., 2008].

It was shown in $S$. aureus, that the two genes agrD and agrB mediate the biosynthesis of AIPs [Ji et al., 1995]. The gene $\operatorname{agrD}$ encodes a precursor peptide consisting of a core peptide that is flanked by an N-terminal amphipathic helical region and a C-terminal highly negatively charged recognition sequence [Thoendel and Horswill, 2009]. AgrD is processed by AgrB, a membrane protein with endopeptidase activity, and an additional protease that is thought to be SpsB, the general signal peptidase associated with Sec and Tat secretion system [Hazenbos et al., 2017), via the following (proposed) pathway [Thoendel and Horswill, 2009]: Upon translation, the precursor peptide localizes to the inner leaflet of the cell membrane via the $\mathrm{N}$-terminal amphipathic helix structure [Zhang et al., 2004]. In the next step, AgrB removes the C-terminal recognition sequence of the precursor peptide, which is followed by formation of the thiolactone ring between a Cys of the core peptide and its C-terminus [Thoendel and Horswill, 2009]. By means of a yet unknown mechanism, the AIP precursor is translocated to the outer cytoplasmic membrane leaflet, either by AgrB or another protein, where the N-terminal amphipathic helix is subsequently removed, presumably by the peptidase SpsB, which results in the release of the mature AIP [Kavanaugh et al., 2007].

Although the agr QS system is present in all staphylococci, the length and amino acid compositions of AIP 
Table 2. Amino acids sequences of autoinducing peptides (AIPs) produced by Staphylococcus species

\begin{tabular}{|c|c|c|c|}
\hline Species & Sequence & Inhibited Agr & Source \\
\hline S. argenteus & YSTCDFIM (identical to S. aureus AIP-I) & & [Gless et al., 2019] \\
\hline \multirow{2}{*}{ S. aureus } & GVNACSSLF (AIP-II) & S. aureus Agr-I/III/IV & [Ji et al., 1997] \\
\hline & YSTCYFIM (AIP-IV) & $\begin{array}{l}\text { S. aureus Agr-II/III } \\
\text { S. simulans Agr-III } \\
\text { S. epidermidis Agr-I }\end{array}$ & $\begin{array}{l}\text { [Jarraud et al., 2000; Otto et al., 2001; } \\
\text { Brown et al., 2020] }\end{array}$ \\
\hline S. caprae & YSTCSYYF & S. aureus Agr-I/II/II/IV & [Paharik et al., 2017] \\
\hline S. chromogenes & SINPCTGFF & & [Gless et al., 2019] \\
\hline S. epidermidis & NAAKYNPCASYL (AIP-III) & $\begin{array}{l}\text { S. epidermidis Agr-I } \\
\text { S. aureus Agr-I }\end{array}$ & [Olson et al., 2014; Williams et al., 2019] \\
\hline S. haemolyticus & SFTPCTTYF & & [Gless et al., 2019] \\
\hline \multirow[t]{2}{*}{ S. hominis } & TYSTCYGYF & & [Gless et al., 2019] \\
\hline & SYNVCGGYF & S. aureus Agr-I & [Williams et al., 2019] \\
\hline S. hyicus & KINPCTVFF & & [Gless et al., 2019] \\
\hline \multirow[t]{2}{*}{ S. lugdunensis } & DICNAYF & S. aureus Agr-I/II/III & [Ji et al., 1997; Otto et al., 2001] \\
\hline & DMCNGYF (AIP-II) & & [Gless et al., 2019] \\
\hline \multirow{2}{*}{ S. simulans } & KYYPCWGYF (AIP-II) & $\begin{array}{l}\text { S. simulans Agr-I } \\
\text { S. aureus Agr-I/II/III/IV }\end{array}$ & [Brown et al., 2020] \\
\hline & KYNPCWGYF (AIP-III) & $\begin{array}{l}\text { S. simulans Agr-I } \\
\text { S. aureus Agr-I/II/III }\end{array}$ & [Brown et al., 2020] \\
\hline S. vitulinus & VIRGCTAFL & & [Gless et al., 2019] \\
\hline S. warneri & YSPCTNFF & & [Gless et al., 2019] \\
\hline
\end{tabular}

precursors/mature AIPs are highly diverse between different staphylococcal species and, intriguingly, also between different clonal groups of a given species [Le and Otto, 2015]. In S. aureus, for instance, four agr types with four different AIPs (AIP I-IV) are known that show crossinhibition towards strains possessing other agr types, a phenomenon called "quorum quenching," that also oc- curs on the interspecies level [Ji et al., 1997; Otto et al., 1999; Paharik et al., 2017]. The amino acid sequences of AIPs produced by staphylococci are summarized in Table 2, including also the AIP variant of Staphylococcus pseudintermedius, where the thiolactone is replaced by a lactone, and Figure 3 shows representative AIP structures. 


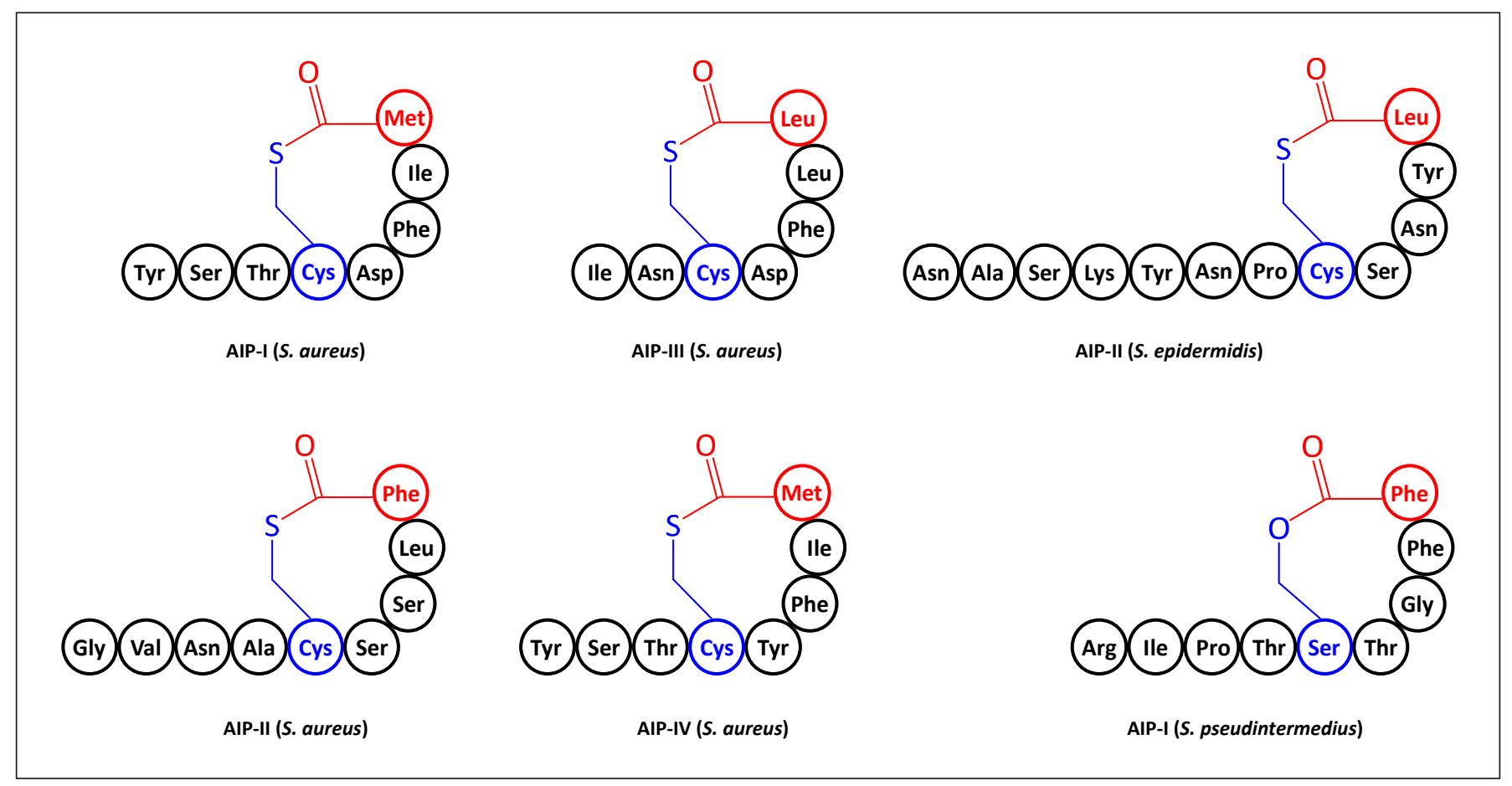

Fig. 3. Amino acid sequence and ring topologies/structures of (staphylococcal) autoinducing peptides. Thiolacte and lactone rings formed between amino acids are indicated in blue (Cys/Ser) and red (AA).

\section{NRPs (Non-Ribosomal Peptides)}

Non-ribosomal peptides are secondary metabolites found in bacteria and fungi with manifold biological activities [Finking and Marahiel, 2004]. In contrast to RiPPs described above, NRPs are produced by non-ribosomal peptide synthetases (NRPSs), a family of large multimodular mega-enzymes; thus, NRPSs constitute RNA- and ribosome-independent machineries for peptide biosynthesis.

NRPSs are typically organized in multiple, distinct modules comprising catalytic domains that are responsible for the coordinated incorporation of a single amino acid or related building block into a polypeptide product. Those modules can either be encoded by a single gene to form a single, large NRPS protein with multiple modules, or by multiple genes encoding individual NRPS proteins that interact sequentially with each other to form a multienzyme complex [Finking and Marahiel, 2004; Gulick, 2017]. A minimal module, usually found as the first module initiating peptide synthesis, consists of an adenylation (A) and a peptidyl carrier protein (PCP) domain, while modules further downstream generally also contain an additional condensation (C) domain. NRP biosynthesis comprises several biochemical steps that are described at greater detail elsewhere [Finking and Marahiel, 2004; Gulick, 2017].

In brief: The A domain is responsible for the selection of the amino acid to be incorporated into the NRPS product and is therefore often referred to as the "gate keeper" of NRPSs [Stachelhaus et al., 1999; Gulick, 2017]. During NRP synthesis, the A domain activates the amino acid in an ATP-dependent manner to form an amino acyl adenylate that is loaded onto a PCP. The $\mathrm{C}$-domain is then responsible for the elongation/extension of the NRP as it catalyzes the peptide bond formation between the two amino acyl adenylates tethered to PCPs of adjacent modules [Stachelhaus et al., 1998; Finking and Marahiel, 2004]. This new peptide serves again as a substrate for the further downstream located $\mathrm{C}$-domains, continuing the elongation process. At the end of the elongation process, release of the nascent peptide from the last PCP is usually catalyzed by a thioesterase domain but can occasionally also be catalyzed by a reductase domain [Finking and Marahiel, 2004; Du and Lou, 2010]. In case of the latter, the hitherto identified NRPs from staphylococci are released via an NADPHdependent reductase. 


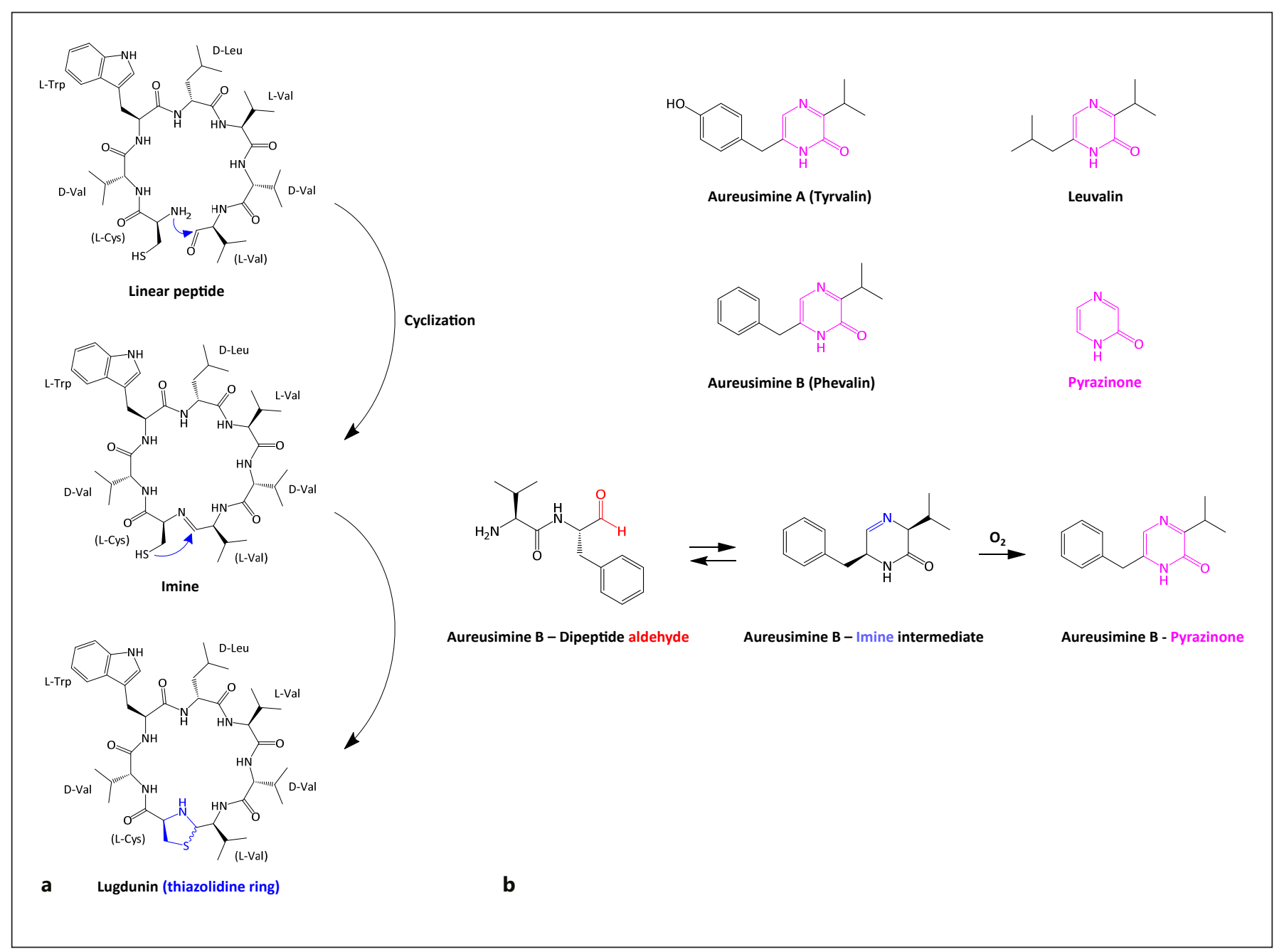

Fig. 4. Community active NRPS products of staphylococci. a Chemical structure of the fibupeptide lugdunin and its conversion from a linear peptide, over an imine intermediate to the final lugdunin product. Thiazolidine ring is indicated in blue. $\mathbf{b}$ Chemical structures of aureusimines and their conversion from a dipeptide aldehyde (red), over an imine intermediate (blue) to a pyrazinone product (pink), on the example of aureusimine B.

\section{Fibupeptides}

Fibupeptides are a recently discovered class of NRPs defined as macrocyclic peptides containing a thiazolidine moiety [Schilling et al., 2019]. This class is represented by lugdunin, currently the first and only member of natural fibupeptides (Fig. 4a, Table 1) [Zipperer et al., 2016]. Lugdunin has protonophore activity combined with antibiotic properties. It is produced by Staphylococcus lugdunensis, a commensal of the human nose and skin microbiomes that inhibits the growth of $S$. aureus (among other bacteria) by causing the breakdown of energy supply. Furthermore, it could be shown that the risk of nasal carriage of $S$. aureus was approx. 6-fold reduced when human individuals were colonized by lugdunin-produc- ing S. lugdunensis, which was also confirmed in animal models, indicating a microbiome-shaping role of lugdunin-producing $S$. lugdunensis that may contribute to human resilience against $S$. aureus carriage [Zipperer et al., 2016].

The lugdunin BGC is located on the chromosome and contains the genes responsible for lugdunin biosynthesis; the four genes $\operatorname{lug} A-D$, encoding the NRPS modules, and the genes $\operatorname{lug} T$ and $\operatorname{lug} Z$, encoding a thioesterase involved in repair/recovery of stalled PCP domains and a $4^{\prime}$-phosphopantetheinyl transferase, respectively. It further contains genes involved in lugdunin transport and immunity $($ lugI-H) or, presumably, regulation (lugJ, lugR) [Zipperer et al., 2016; Krauss et al., 2020]. 
The four NRPS modules of LugA-D contain five adenylation domains for Cys, Val, Trp, Leu, Val and also three epimerization domains, which catalyze the conversion of $\mathrm{L}$-amino acids to $\mathrm{D}$-amino acids. The biosynthesis is initiated by LugD and continues with LugA-C, with LugC contributing three $\mathrm{Val}$, resulting in the formation of a linear hepta-peptide consisting of L-Cys, D-Val, LTrp, D-Leu, L-Val, D-Val, and L-Val, tethered to the last PCP of LugC. The C-terminal reductase of LugC releases the peptide from the last PCP, leading to aldehyde formation at the $\mathrm{C}$-terminal $\mathrm{L}$-Val that is subsequently nucleophilically attacked by the N-terminal amine of L-Cys to form a macrocyclic imine. A second nucleophilic attack of the thiol group of Cys to the imine finally generates the five-membered thiazolidine heterocycle, the hallmark of fibupeptides [Zipperer et al., 2016].

\section{Pyrazinones}

Pyrazinones are 6-membered, nitrogenous heterocycles that are constituents of aureusimines, non-ribosomally synthesized, cyclic dipeptides produced by some Staphylococcus species. Aureusimines were discovered almost simultaneously by the two groups of Fischbach [Zimmermann and Fischbach, 2010] and Magarvey [Wyatt et al., 2010] in S. aureus, and their BGCs were shown to be conserved in several staphylococcal species including S. aureus, S. epidermidis, S. lugdunensis, and S. capitis [Zimmermann and Fischbach, 2010].

The BGC of aureusimine is located on the chromosome and consists of genes coding for the $4^{\prime}$-phosphopantetheinyl transferase AusB and the single, dimodular NRPS protein AusA, whose first A domain has a preference for incorporation of $\mathrm{Val}$ and the second $\mathrm{A}$ domain for the aromatic amino acids Tyr or Phe and the aliphatic amino acid Leu [Wyatt et al., 2010; Wilson et al., 2013]. Biosynthesis leads to a dipeptide consisting of L-Val and either L-Tyr, L-Phe, or L-Leu that is released from the last PCP via the C-terminal reductase. The resulting aldehyde at L-Tyr/L-Phe/L-Leu subsequently undergoes cyclization with the amine of the $\mathrm{N}$-terminal $\mathrm{L}-\mathrm{V}$ al to form an intermediate imine that again spontaneously oxidizes to the final pyrazinone product, aureusimine A (tyrvalin), aureusimine B (phevalin), or leuvalin, respectively (Fig. 4b) [Wyatt et al., 2010; Zimmermann and Fischbach, 2010].

The biological roles of aureusimines have been investigated by several groups, which initially thought that these compounds are involved in virulence factor regulation, which, however, was later attributed to a mutation in the saeS gene, a known regulator of virulence factors
[Sun et al., 2010; Wyatt et al., 2010]. Nevertheless, aureusimines may play a role in $S$. aureus virulence. The group of Fraunholz [Blättner et al., 2016] has shown that aureusimines are involved in PSM-mediated phagosomal escape of internalized $S$. aureus in a currently unknown way and therefore contribute to an important survival strategy. More recently, a study based on the investigation of NRPS BGCs of the human gut microbiome suggested that peptide aldehydes, such as the aureusimine B aldehyde, are also potent inhibitors of cathepsins, a cysteine protease family involved in Toll-like receptor 9 activation in macrophages and dendritic cells and in antigen processing and presentation [Gulick, 2017; Guo et al., 2017]. Interestingly, the linear dipeptide aldehyde seems to be the bioactive form rather than the cyclic pyrazinone peptide. The gut represents an anaerobic environment, where the linear dipeptide and the cyclic imine exist in equilibrium [Guo et al., 2017]. Only in the presence of oxygen, the irreversible conversion from the cyclic imine to the pyrazinone occurs, suggesting that the pyrazinone variant may be the unfavorable form of aureusimines. If aureusimines are also inhibitors of host cysteine proteases and whether this potential activity contributes to the prevention of PSM degradation or of antigen processing remains to be explored.

\section{Polycarboxylate Siderophores}

(Poly-)carboxylates are one of the four known classes of siderophores, low-molecular-weight molecules with ferric iron-chelating properties. They were classified based on the chemical moieties with which they coordinate $\mathrm{Fe}$ (III), as described in more detail elsewhere [Kramer et al., 2020]. Siderophores are produced by bacteria under iron-limited conditions to secure proliferation by scavenging iron ions from the environment. In staphylococci, staphyloferrin A and B have been documented, which belong to the (poly)carboxylate class of siderophores (Fig. 5a) [Konetschny-Rapp et al., 1990; Drechsel et al., 1993]. While many siderophores are produced by NRPS systems, staphyloferrin A and B are produced via NRPS-independent siderophore (NIS) synthetases.

NIS enzymes catalyze the condensation of citric acid or derivatives with amines or alcohols, and are characterized by a conserved $\mathrm{N}$-terminal iron uptake chelate (Iuc) domain and a C-terminal domain associated with iron transport or metabolism [Carroll and Moore, 2018].

Only two and three NIS enzymes are required for synthesis of staphyloferrin A and B, respectively [Oves-Cos- 
<smiles>O=C(O)C[C@@](O)(CC(=O)N[C@@H](CCCNC(=O)C[C@@](O)(CC(=O)O)C(=O)O)C(=O)O)C(=O)O</smiles>

a

Staphyloferrin A<smiles>NC(CNC(=O)CC(O)(CC(=O)NCCNC(=O)CCC(=O)C(=O)O)C(=O)O)C(=O)O</smiles>

Staphyloferrin B

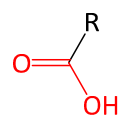

Carboxylate<smiles>CC(NC(CCNC(Cc1c[nH]cn1)C(=O)O)C(=O)O)C(=O)O</smiles><smiles>[R]C(NC([R2])C(=O)O)C(=O)O</smiles>

b

Fig. 5. Metallophores produced by staphylococci. a Chemical structures of the two siderophores staphyloferrin $\mathrm{A}$ and B. Carboxylates are depicted and indicated in red. b Chemical structure of staphylopine. The opine scaffold is depicted and indicated in blue.

tales et al., 2009; Carroll and Moore, 2018]. These enzymes are encoded by the genes $s f a B / s f a D$ for staphyloferrin $\mathrm{A}$ [Beasleyetal.,2009; Cotton etal.,2009] and $s b n E / s b n C / s b n F$ for staphyloferrin B [Dale et al., 2004; Cheung et al., 2009], which are found adjacent to genes coding for proteins involved in siderophore export and uptake. While the gene locus for staphyloferrin B seems to be limited to only a few staphylococcal species such as $S$. aureus, $S$. pseudintermedius, or S. hyicus, the genes of staphyloferrin A seem to be present in almost all staphylococcal species. Only some species such as $S$. lugdunensis lack of $s f a A$ and $s f a D$, suggesting that these species do not produce their own siderophores. Nevertheless, S. lugdunensis encodes the uptake systems for both, staphyloferrin A and staphyloferrin $\mathrm{B}$ allowing to sequester siderophores from other microbiome member species [Brozyna et al., 2014].

Staphyloferrin A is composed of two citric acid moieties that are linked to a D-ornithine [Konetschny-Rapp et al., 1990] (Fig. 5 a). The biosynthesis of staphyloferrin A can be divided into two steps and is initiated by $\mathrm{SfaD}$ that connects a citrate with a D-ornithine to generate a citryl-D-ornithine intermediate in an ATP and $\mathrm{Mg}^{2+}$-dependent manner. In the second step, SfaB adds another citrate to the intermediate, resulting in the formation of staphyloferrin A.

Staphyloferrin B consists of L-2,3-diaminopropionic acid (L-Dap), citrate, 1,2-diaminoethane, and a-ketoglutarate and is synthesized by the SbnCEF NIS and the PLP-decarboxylase SbnH [Drechsel et al., 1993; Cheung et al., 2009]. Here, SbnE connects a citrate with L-Dap to form a citryl-diaminopropionic acid intermediate, which is decarboxylated by $\mathrm{SbnH}$ to a citryl-diaminethane. SbnF then adds another L-Dap to the intermediate and $\mathrm{SbnC}$ completes staphyloferrin B biosynthesis by adding $\alpha$-ketoglutarate to the decarboxylated Dap residue [Cheung et al., 2009; Carroll and Moore, 2018].

\section{Opines (Metallophore)}

Opines are nitrogenous compounds with diverse biological roles that consist of a variety of $\alpha$-keto acid and amino acid substrates. The synthesis of opines is usually mediated by opine dehydrogenases that catalyze the condensation of the amino group of an amino acid with an a-keto acid and a subsequent $\mathrm{NAD}(\mathrm{P}) \mathrm{H}$ dependent re- 
duction [McFarlane et al., 2018]. Recently, a novel opine compound produced by $S$. aureus has been identified that was termed staphylopine (Fig. 5b) [Ghssein et al., 2016].

Staphylopine is a broad-spectrum metallophore with a nicotianamine-like entity responsible for its metal-chelating properties, showing binding affinities for nickel, copper, cobalt, iron, and zinc. It is produced under zinclimited conditions and has been shown to play an important role in zinc acquisition, virulence, and fitness of $S$. aureus [Ding et al., 2012; Remy et al., 2013; Ghssein et al., 2016; Grim et al., 2017].

The BGC of staphylopine consists of the three genes, cntKLM, that are encoded adjacent to genes involved in staphylopine export, cntE, and recognition and import, cntABCDF [Ghssein et al., 2016]. The staphylopine biosynthesis is initiated by the His racemase $c n t K$ that provides a $\mathrm{D}$-His, which is connected by the nicotianamine synthase CntL to SAM, generating a D-His-nicotianamine (D-HisNA) intermediate. In the last step, the opine dehydrogenase CtnM adds a pyruvate to D-HisNA, followed by a NADPH-dependent reduction, resulting in the mature staphylopine molecule [Ghssein et al., 2016; McFarlane et al., 2018].

\section{Conclusion}

Bacterial communities of the human microbiome comprise a multitude of bacterial species and we are only just starting to decipher the mechanisms shaping their compositions. In this context, aside from host-bacteria interactions, specific secondary metabolites may play an important role in bacteria-bacteria interactions [Otto, 2020]. On many occasions, staphylococci have demonstrated to be a rich source of versatile bioactive compounds, including metallophores, bacteriocins, and signaling-interfering AIPs, which are produced by a large repertoire of biosynthetic pathways.

However, whereas a lot of these compounds have been thoroughly studied with respect to their bioactive properties in vitro, their ecological relevance for bacterial interactions in vivo remains widely elusive. This fact is due to at least two main reasons. Firstly, research on staphylococci has focused largely on infections, caused by $S$. aureus and only a few other species [Lowy, 1998], while the commensal lifestyle has been addressed only by a few studies. Secondly, interactions within bacterial communities are complex, require sophisticated model systems, and are difficult to study with standard laboratory methodology. Members of bacterial communities on human body surfaces have to deal with cocktails of different secondary metabolites produced by many different host and bacterial cells. Therefore, it is often challenging to pinpoint the impact of individual compounds or their producers on community composition and dynamic. New model systems simulating complex bacterial communities under realistic conditions that allow the dynamic monitoring of fitness traits of individual bacterial clones need to be developed.

Despite these difficulties, the interest in the field of functional microbiome science is continuously increasing owing to recent advances in techniques, such as next-generation sequencing, metagenome analyses, metabolomics, and suitable in vivo models [Otto, 2020]. A better understanding of the biological roles of specific secondary metabolites in bacterial interactions, however, requires further advances in these techniques. Such developments will not only facilitate to elucidate the role of novel compounds, but also to examine compounds that have been identified in the past but have not been investigated in terms of their significance for bacterial interactions yet.

Furthermore, staphylococci and their potent bioactive compounds may become of interest for translational medicine. Bacteriocins, in particular, seem to be prevalent among staphylococci, and recent studies have shown that staphylococci are a reservoir of new bacteriocins of different and often novel substance classes [Janek et al., 2016; Nakatsuji et al., 2017; Angelopoulou et al., 2020]. Thus, either isolated bacteriocins or the bacteriocin producer strains may become useful alternatives or complementary agents for clinically used antibiotics for infection treatment or as probiotics for pathogen decolonization strategies. In addition, QS-inhibitory AIP variants may become attractive anti-virulence drugs, since they interfere with the staphylococcal agr systems that regulate virulence-associated genes and, hence, may prevent infections or attenuate their severity.

\section{Acknowledgments}

The authors thank their coworkers and collaborators for helpful discussion.

\section{Conflict of Interest Statement}

Eberhard Karls University Tübingen holds a patent (EP3072899B1) covering the compound lugdunin, derivatives thereof, and the bacterial infection prevention by lugdunin-producing bacteria. The patent has also been filed in the USA (US2018/0155397A1). 


\section{Funding Sources}

Our work is funded by the Deutsche Forschungsgemeinschaft (DFG, German Research Foundation) under Germany's Excellence Strategy - EXC 2124 - 390838134 'Controlling Microbes to Fight Infections' (S.H., A.P., B.K.), GRK1708 (S.H., A.P.), TRR261 (S.H., A.P.), and TRR156 (A.P.); by the German Center of Infection Research (DZIF) to S.H., A.P., B.K..; and the European Innovative Medicines Initiative IMI (COMBACTE) (A.P.).

\section{Author Contributions}

All authors contributed to the preparation of this document and their contributions according to the authorship criteria are as follows. B.O.T.S.: drafting the work and preparation of figures. S.H., A.P., and B.K.: substantial contributions to the conception and design of the work and revising the work critically for important intellectual content. All authors gave final approval of the version to be published.

\section{References}

Allgaier HJG, Werner R, Schneider U, Zähner H. Strukturaufklärung von Epidermin, einem ribosomal synthetisierten, heterodet tetracyclischen Polypeptid-Antibioticum. Angewandte Chemie (International ed in English). 1985;97(12):1052-54.

Angelopoulou A, Warda AK, O'Connor PM, Stockdale SR, Shkoporov AN, Field D, et al. Diverse Bacteriocins Produced by Strains From the Human Milk Microbiota. Front Microbiol. 2020 May 19;11(788):788.

Arnison PG, Bibb MJ, Bierbaum G, Bowers AA, Bugni TS, Bulaj G, et al. Ribosomally synthesized and post-translationally modified peptide natural products: overview and recommendations for a universal nomenclature. Nat Prod Rep. 2013 Jan;30(1):108-60.

Asaduzzaman SM, Nagao J, Iida H, Zendo T, Nakayama J, Sonomoto K. Nukacin ISK-1, a bacteriostatic lantibiotic. Antimicrob Agents Chemother. 2009 Aug;53(8):3595-8.

Aso Y, Sashihara T, Nagao J, Kanemasa Y, Koga $\mathrm{H}$, Hashimoto $\mathrm{T}$, et al. Characterization of a gene cluster of Staphylococcus warneri ISK-1 encoding the biosynthesis of and immunity to the lantibiotic, nukacin ISK-1. Biosci Biotechnol Biochem. 2004 Aug;68(8):1663-71.

Bagley MC, Dale JW, Merritt EA, Xiong X. Thiopeptide Antibiotics. Chem Rev. 2005;105(2): 685-714.

Bastos MC, Ceotto H, Coelho ML, Nascimento JS. Staphylococcal antimicrobial peptides: relevant properties and potential biotechnological applications. Curr Pharm Biotechnol. 2009 Jan;10(1):38-61.

Beasley FC, Vinés ED, Grigg JC, Zheng Q, Liu S, Lajoie GA, et al. Characterization of staphyloferrin A biosynthetic and transport mutants in Staphylococcus aureus. Mol Microbiol. 2009 May;72(4):947-63.

Becker K, Heilmann C, Peters G. Coagulase-Negative Staphylococci. Clin Microbiol Rev. 2014; 27(4):870

Bennallack PR, Bewley KD, Burlingame MA, Robison RA, Miller SM, Griffitts JS. Reconstitution and Minimization of a Micrococcin Biosynthetic Pathway in Bacillus subtilis. J Bacteriol. 2016 Sep 15;198(18):2431-8.

Bennallack PR, Burt SR, Heder MJ, Robison RA, Griffitts JS. Characterization of a novel plasmid-borne thiopeptide gene cluster in Staphylococcus epidermidis strain 115. J Bacteriol. 2014 Dec;196(24):4344-50.
Bewley KD, Bennallack PR, Burlingame MA, Robison RA, Griffitts JS, Miller SM. Capture of micrococcin biosynthetic intermediates reveals C-terminal processing as an obligatory step for in vivo maturation. Proc Natl Acad Sci U S A. 2016 Nov 1;113(44):12450-5.

Bierbaum G, Götz F, Peschel A, Kupke T, van de Kamp M, Sahl HG. The biosynthesis of the lantibiotics epidermin, gallidermin, Pep5 and epilancin K7. Antonie van Leeuwenhoek. 1996 Feb;69(2):119-27.

Bierbaum G, Sahl HG. Lantibiotics: Mode of Action, Biosynthesis and Bioengineering. Curr Pharm Biotechnol. 2009;10(1):2-18.

Blättner S, Das S, Paprotka K, Eilers U, Krischke M, Kretschmer D, et al. Staphylococcus aureus Exploits a Non-ribosomal Cyclic Dipeptide to Modulate Survival within Epithelial Cells and Phagocytes. PLoS Pathog. 2016 Sep; 12(9):e1005857.

Bonelli RR, Schneider T, Sahl HG, Wiedemann I. Insights into in vivo activities of lantibiotics from gallidermin and epidermin mode-of-action studies. Antimicrob Agents Chemother. 2006 Apr;50(4):1449-57.

Botelho-Nevers E, Gagnaire J, Verhoeven PO, Cazorla C, Grattard F, Pozzetto B, et al. Decolonization of Staphylococcus aureus carriage. Med Mal Infect. 2017 Sep;47(5):30510.

Braga RM, Dourado MN, Araújo WL. Microbial interactions: ecology in a molecular perspective. Braz J Microbiol. 2016 Dec;47(Suppl 1Suppl 1):86-98.

Breukink E, Wiedemann I, van Kraaij C, Kuipers OP, Sahl HG, de Kruijff B. Use of the Cell Wall Precursor Lipid II by a Pore-Forming Peptide Antibiotic. Science. 1999;286(5448):2361.

Brötz H, Bierbaum G, Leopold K, Reynolds PE, Sahl HG. The Lantibiotic Mersacidin Inhibits Peptidoglycan Synthesis by Targeting Lipid II. Antimicrob Agents Chemother. 1998; 42(1):154.

Brown MM, Kwiecinski JM, Cruz LM, Shahbandi A, Todd DA, Cech NB, et al. Novel Peptide from Commensal Staphylococcus simulans Blocks Methicillin-Resistant Staphylococcus aureus Quorum Sensing and Protects Host Skin from Damage. Antimicrob Agents Chemother. 2020;64(6):e00172-20.

Brozyna JR, Sheldon JR, Heinrichs DE. Growth promotion of the opportunistic human pathogen, Staphylococcus lugdunensis, by heme, hemoglobin, and coculture with Staphylococcus aureus. Microbiologyopen. 2014; 3(2):182-95.

Canovas J, Baldry M, Bojer MS, Andersen PS, Grzeskowiak PK, Stegger M, et al. Cross-Talk between Staphylococcus aureus and Other Staphylococcal Species via the agr Quorum Sensing System. Front Microbiol. 2016 Nov; 7(1733): 1733 .

Carnio MC, Höltzel A, Rudolf M, Henle T, Jung $\mathrm{G}$, Scherer S. The macrocyclic peptide antibiotic micrococcin $\mathrm{P}(1)$ is secreted by the foodborne bacterium Staphylococcus equorum WS 2733 and inhibits Listeria monocytogenes on soft cheese. Appl Environ Microbiol. 2000; 66(6):2378-84.

Carroll CS, Moore MM. Ironing out siderophore biosynthesis: a review of non-ribosomal peptide synthetase (NRPS)-independent siderophore synthetases. Crit Rev Biochem Mol Biol. 2018 Aug;53(4):356-81.

Ceotto H, Holo H, da Costa KF, Nascimento JS, Salehian Z, Nes IF, et al. Nukacin 3299, a lantibiotic produced by Staphylococcus simulans 3299 identical to nukacin ISK-1. Vet Microbiol. 2010 Nov;146(1):124-31.

Cheung J, Beasley FC, Liu S, Lajoie GA, Heinrichs DE. Molecular characterization of staphyloferrin B biosynthesis in Staphylococcus aureus. Mol Microbiol. 2009 Nov; 74(3):594-608.

Christensen GJ, Scholz CF, Enghild J, Rohde H, Kilian M, Thürmer A, et al. Antagonism between Staphylococcus epidermidis and Propionibacterium acnes and its genomic basis. BMC Genomics. 2016 Feb 29;17:152.

Claesen J, Spagnolo JB, Ramos SF, Kurita KL, Byrd AL, Aksenov AA, et al. A Cutibacterium acnes antibiotic modulates human skin microbiota composition in hair follicles. Sci Transl Med. 2020 Nov 18;12(570):12.

Coates R, Moran J, Horsburgh MJ. Staphylococci: colonizers and pathogens of human skin. Future Microbiol. 2014;9(1):75-91.

Cotter PD, Hill C, Ross RP. Bacteriocins: developing innate immunity for food. Nat Rev Microbiol. 2005a Oct;3(10):777-88.

Cotter PD, O'Connor PM, Draper LA, Lawton EM, Deegan LH, Hill C, et al. Posttranslational conversion of $\mathrm{L}$-serines to $\mathrm{D}$-alanines is vital for optimal production and activity of the lantibiotic lacticin 3147. Proc Natl Acad Sci U S A. 2005b;102(51):18584-9. 
Cotton JL, Tao J, Balibar CJ. Identification and Characterization of the Staphylococcus aureus Gene Cluster Coding for Staphyloferrin A. Biochemistry. 2009 Feb;48(5):1025-35.

Crupper SS, Gies AJ, Iandolo JJ. Purification and characterization of staphylococcin BacR1, a broad-spectrum bacteriocin. Appl Environ Microbiol. 1997 Nov;63(11):4185-90.

Cundliffe E, Thompson J. Concerning the mode of action of micrococcin upon bacterial protein synthesis. Eur J Biochem. 1981 Aug; 118(1):47-52.

Dale SE, Doherty-Kirby A, Lajoie G, Heinrichs DE. Role of siderophore biosynthesis in virulence of Staphylococcus aureus: identification and characterization of genes involved in production of a siderophore. Infect Immun. 2004 Jan;72(1):29-37.

Daly KM, Upton M, Sandiford SK, Draper LA, Wescombe PA, Jack RW, et al. Production of the Bsa lantibiotic by community-acquired Staphylococcus aureus strains. J Bacteriol. 2010;192(4):1131-42.

Ding Y, Fu Y, Lee JC, Hooper DC. Staphylococcus aureus NorD, a putative efflux pump coregulated with the Opp1 oligopeptide permease, contributes selectively to fitness in vivo. J Bacteriol. 2012 Dec;194(23):6586-93.

Drechsel H, Freund S, Nicholson G, Haag H, Jung $\mathrm{O}$, Zähner $\mathrm{H}$, et al. Purification and chemical characterization of staphyloferrin B, a hydrophilic siderophore from staphylococci. Biometals. 1993 Autumn;6(3):185-92.

$\mathrm{Du}$ L, Lou L. PKS and NRPS release mechanisms. Nat Prod Rep. 2010 Feb;27(2):255-78.

Duarte AFS, Ceotto-Vigoder H, Barrias ES, Souto-Padrón TCBS, Nes IF, Bastos MDCF. Hyicin 4244 , the first sactibiotic described in staphylococci, exhibits an anti-staphylococcal biofilm activity. Int J Antimicrob Agents. 2018 Mar;51(3):349-56.

Duarte AFd. S, Ceotto H, Coelho MLV, Brito MAV, Bastos Md. Cd. F. Identification of new staphylococcins with potential application as food biopreservatives. Food Control. 2013 Jul; 32(1):313-21.

Ekkelenkamp MB, Hanssen M, Danny Hsu ST, de Jong A, Milatovic D, Verhoef J, et al. Isolation and structural characterization of epilancin 15X, a novel lantibiotic from a clinical strain of Staphylococcus epidermidis. FEBS Lett. 2005;579(9):1917-22.

Ersfeld-Dressen H, Sahl HG, Brandis H. Plasmid involvement in production of and immunity to the staphylococcin-like peptide Pep 5. J Gen Microbiol. 1984 Nov;130(11) 3029-35.

Fagundes PC, Ceotto H, Potter A, Vasconcelos de Paiva Brito MA, Brede D, Nes IF, et al. Hyicin 3682 , a bioactive peptide produced by Staphylococcus hyicus 3682 with potential applications for food preservation. Res Microbiol. 2011 Dec;162(10):1052-9.

Fagundes PC, Francisco MS, Sousa Santos IN, Marques-Bastos SLS, Paz JAS, Albano RM, et al. Draft genome sequence of Staphylococcus agnetis 3682, the producing strain of the broad-spectrum lantibiotic agneticin 3682. J Glob Antimicrob Resist. 2019 Dec;19:50-2.

Finking R, Marahiel MA. Biosynthesis of nonribosomal peptides1. Annu Rev Microbiol. 2004;58:453-88.

Flowers L, Grice EA. The Skin Microbiota: Balancing Risk and Reward. Cell Host Microbe. 2020 Aug;28(2):190-200.

Flühe L, Knappe TA, Gattner MJ, Schäfer A, Burghaus O, Linne U, et al. The radical SAM enzyme AlbA catalyzes thioether bond formation in subtilosin A. Nat Chem Biol. 2012 Feb 26;8(4):350-7.

Furmanek B, Kaczorowski T, Bugalski R, Bielawski K, Bohdanowicz J, Podhajska AJ, et al. Identification, characterization and purification of the lantibiotic staphylococcin $\mathrm{T}$, a natural gallidermin variant. J Appl Microbiol. 1999 Dec;87(6):856-66.

Geissler S, Götz F, Kupke T. Serine protease EpiP from Staphylococcus epidermidis catalyzes the processing of the epidermin precursor peptide. J Bacteriol. 1996;178(1):284-8.

Ghssein G, Brutesco C, Ouerdane L, Fojcik C, Izaute A, Wang S, et al. Biosynthesis of a broadspectrum nicotianamine-like metallophore in Staphylococcus aureus. Science. 2016 May 27; 352(6289):1105-9.

Gless BH, Bojer MS, Peng P, Baldry M, Ingmer H, Olsen CA. Identification of autoinducing thiodepsipeptides from staphylococci enabled by native chemical ligation. Nat Chem. 2019 May; 11(5):463-9.

Götz F, Perconti S, Popella P, Werner R, Schlag M. Epidermin and gallidermin: Staphylococcal lantibiotics. Int J Med Microbiol. 2014 Jan; 304(1):63-71

Grice EA, Segre JA. The skin microbiome. Nat Rev Microbiol. 2011;9(4):244-53.

Grim KP, San Francisco B, Radin JN, Brazel EB, Kelliher JL, Párraga Solórzano PK, et al. The Metallophore Staphylopine Enables Staphylococcus aureus To Compete with the Host for Zinc and Overcome Nutritional Immunity. mBio. 2017 Oct 31;8(5).

Guder A, Wiedemann I, Sahl HG. Posttranslationally modified bacteriocins -- the lantibiotics. Biopolymers. 2000;55(1):62-73. Peptide Science

Gulick AM. Nonribosomal peptide synthetase biosynthetic clusters of ESKAPE pathogens. Nat Prod Rep. 2017;34(8):981-1009.

Guo CJ, Chang FY, Wyche TP, Backus KM, Acker TM, Funabashi M, et al. Discovery of Reactive Microbiota-Derived Metabolites that Inhibit Host Proteases. Cell. 2017;168(3):517e18.

Harms JM, Wilson DN, Schluenzen F, Connell SR, Stachelhaus T, Zaborowska Z, et al. Translational regulation via L11: molecular switches on the ribosome turned on and off by thiostrepton and micrococcin. Mol Cell. $2008 \mathrm{Apr}$ 11;30(1):26-38.

Hazenbos WL, Skippington E, Tan MW. Staphylococcus aureus type I signal peptidase: essential or not essential, that's the question. Microb Cell. 2017;4(4):108-11.
Heffron SE, Jurnak F. Structure of an EF-Tu complex with a thiazolyl peptide antibiotic determined at 2.35 A resolution: atomic basis for GE2270A inhibition of EF-Tu. Biochemistry. 2000 Jan 11;39(1):37-45.

Heidrich C, Pag U, Josten M, Metzger J, Jack RW, Bierbaum G, et al. Isolation, Characterization, and Heterologous Expression of the Novel Lantibiotic Epicidin 280 and Analysis of Its Biosynthetic Gene Cluster. Appl Environ Microbiol. 1998;64(9):3140.

Islam MR, Nishie M, Nagao J, Zendo T, Keller S, Nakayama J, et al. Ring A of nukacin ISK-1: a lipid II-binding motif for type-A(II) lantibiotic. J Am Chem Soc. 2012 Feb 29;134(8): 3687-90

Janek D, Zipperer A, Kulik A, Krismer B, Peschel A. High Frequency and Diversity of Antimicrobial Activities Produced by Nasal Staphylococcus Strains against Bacterial Competitors. PLoS Pathog. 2016 Aug;12(8):e1005812.

Jarraud S, Lyon GJ, Figueiredo AM, Lina G, Gérard L, Vandenesch F, et al. Exfoliatin-producing strains define a fourth agr specificity group in Staphylococcus aureus. J Bacteriol. 2000;182(22):6517-22.

Ji G, Beavis R, Novick RP. Bacterial interference caused by autoinducing peptide variants. Science. 1997 Jun 27;276(5321):2027-30.

Ji G, Beavis RC, Novick RP. Cell density control of staphylococcal virulence mediated by an octapeptide pheromone. Proc Natl Acad Sci USA. 1995;92(26):12055-9.

Joo HS, Cheung GY, Otto M. Antimicrobial activity of community-associated methicillin-resistant Staphylococcus aureus is caused by phenol-soluble modulin derivatives. J Biol Chem. 2011 Mar 18;286(11):8933-40.

Just-Baringo X, Albericio F, Álvarez M. Thiopeptide antibiotics: retrospective and recent advances. Mar Drugs. 2014 Jan 17;12(1):317-51.

Kalkum M, Lyon GJ, Chait BT. Detection of secreted peptides by using hypothesis-driven multistage mass spectrometry. Proc Natl Acad Sci U S A. 2003;100(5):2795-800.

Kavanaugh JS, Thoendel M, Horswill AR. A role for type I signal peptidase in Staphylococcus aureus quorum sensing. Mol Microbiol. 2007 Aug;65(3):780-98.

Kellner R, Jung G, Hörner T, Zähner H, Schnell $\mathrm{N}$, Entian KD, et al. Gallidermin: a new lanthionine-containing polypeptide antibiotic. Eur J Biochem. 1988 Oct 15;177(1):53-9.

Kellner R, Jung Gn., Josten M, Kaletta C, Entian K-D, Sahl H-G. Pep5: Structure Elucidation of a Large Lantibiotic. Angew Chem Int Ed Engl. 1989 May;28(5):616-9.

Kimura H, Matsusaki H, Sashihara T, Sonomoto K, Ishizaki A. Purification and Partial Identification of Bacteriocin ISK-1, a New Lantibiotic Produced by Pediococcus sp. ISK-1. Biosci Biotechnol Biochem. 1998a;62(12):2341-5.

Kimura H, Sashihara T, Matsusaki H, Sonomoto K, Ishizaki A. Novel bacteriocin of Pediococcus sp. ISK-1 isolated from well-aged bed of fermented rice bran. Ann N Y Acad Sci. 1998b Dec 13;864:345-8.
Torres Salazar/Heilbronner/Peschel/ Krismer 
Knerr PJ, van der Donk WA. Discovery, Biosynthesis, and Engineering of Lantipeptides. Annu Rev Biochem. 2012 2012/07/07;81(1): 479-505.

Koenig RL, Ray JL, Maleki SJ, Smeltzer MS, Hurlburt BK. Staphylococcus aureus AgrA binding to the RNAIII-agr regulatory region. J Bacteriol. 2004 Nov; 186(22):7549-55.

Konetschny-Rapp S, Jung G, Meiwes J, Zähner $\mathrm{H}$, Staphyloferrin A. Staphyloferrin A: a structurally new siderophore from staphylococci. Eur J Biochem. 1990 Jul 20;191(1): 65-74.

Kordel M, Benz R, Sahl HG. Mode of action of the staphylococcinlike peptide Pep 5: voltage-dependent depolarization of bacterial and artificial membranes. J Bacteriol. 1988 Jan;170(1): 84-8.

Kramer J, Özkaya Ö, Kümmerli R. Bacterial siderophores in community and host interactions. Nat Rev Microbiol. 2020 Mar;18(3): $152-63$.

Krauss S, Zipperer A, Wirtz S, Saur J, Konnerth MC, Heilbronner S, et al. Secretion of and self-resistance to the novel fibupeptide antimicrobial lugdunin by distinct $\mathrm{ABC}$ transporters in Staphylococcus lugdunensis. Antimicrob Agents Chemother. 2020 Oct 26.

Krismer B, Weidenmaier C, Zipperer A, Peschel A. The commensal lifestyle of Staphylococcus aureus and its interactions with the nasal microbiota. Nat Rev Microbiol. 2017 Nov; 15(11):675-87.

Kupke T, Götz F. The enethiolate anion reaction products of EpiD. Pka value of the enethiol side chain is lower than that of the thiol side chain of peptides. J Biol Chem. 1997 Feb 21; 272(8):4759-62.

Kupke T, Kempter C, Gnau V, Jung G, Götz F. Mass spectroscopic analysis of a novel enzymatic reaction. Oxidative decarboxylation of the lantibiotic precursor peptide EpiA catalyzed by the flavoprotein EpiD. J Biol Chem. 1994 Feb 25;269(8):5653-9.

Kupke T, Stevanović S, Sahl HG, Götz F. Purification and characterization of EpiD, a flavoprotein involved in the biosynthesis of the lantibiotic epidermin. J Bacteriol. 1992;174(16): 5354-61.

Le KY, Otto M. Quorum-sensing regulation in staphylococci-an overview. Front Microbiol. 2015 2015-October-27;6(1174):1174.

Lee AS, de Lencastre H, Garau J, Kluytmans J, Malhotra-Kumar S, Peschel A, et al. Methicillin-resistant Staphylococcus aureus. Nat Rev Dis Primers. 2018 May 31;4:18033.

Lina G, Jarraud S, Ji G, Greenland T, Pedraza A, Etienne J, et al. Transmembrane topology and histidine protein kinase activity of AgrC, the agr signal receptor in Staphylococcus aureus. Mol Microbiol. 1998;28(3):655-62.

Liu Y, Liu Y, Du Z, Zhang L, Chen J, Shen Z, et al. Skin microbiota analysis-inspired development of novel anti-infectives. Microbiome. 2020;8(1):85.

Lowy FD. Staphylococcus aureus Infections. N Engl J Med. 1998;339(8):520-32.
Mathur H, Fallico V, O'Connor PM, Rea MC, Cotter PD, Hill C, et al. Insights into the Mode of Action of the Sactibiotic Thuricin CD. Front Microbiol. 2017;8:696-6.

McFarlane JS, Davis CL, Lamb AL. Staphylopine, pseudopaline, and yersinopine dehydrogenases: A structural and kinetic analysis of a new functional class of opine dehydrogenase. J Biol Chem. 2018 May 25;293(21):8009-19.

Meyer C, Bierbaum G, Heidrich C, Reis M, Süling J, Iglesias-Wind MI, et al. Nucleotide sequence of the lantibiotic Pep5 biosynthetic gene cluster and functional analysis of PepP and PepC. Evidence for a role of PepC in thioether formation. Eur J Biochem. 1995 Sep 1; 232(2):478-89.

Minamikawa M, Kawai Y, Inoue N, Yamazaki K. Purification and Characterization of Warnericin RB4, Anti-Alicyclobacillus Bacteriocin, Produced by Staphylococcus warneri RB4. Curr Microbiol. 2005 Jul;51(1):22-6.

Montalban-Lopez M, Scott TA, Ramesh S, Rahman IR, van Heel AJ, Viel JH, et al. New developments in RiPP discovery, enzymology and engineering. Nat Prod Rep. 2021 Jan 1; 38(1):130-239. [not available]

Müller A, Ulm H, Reder-Christ K, Sahl HG, Schneider T. Interaction of type A lantibiotics with undecaprenol-bound cell envelope precursors. Microb Drug Resist. 2012 Jun;18(3): 261-70.

Nakatsuji T, Chen TH, Narala S, Chun KA, Two AM, Yun T, et al. Antimicrobials from human skin commensal bacteria protect against Staphylococcus aureus and are deficient in atopic dermatitis. Sci Transl Med. 2017; 9(378):eaah4680.

Nakatsuji T, Hata TR, Tong Y, Cheng JY, Shafiq F, Butcher AM, et al. Development of a human skin commensal microbe for bacteriotherapy of atopic dermatitis and use in a phase 1 randomized clinical trial. Nat Med. 2021 Feb 22;27:700-709.

Navaratna MA, Sahl HG, Tagg JR. Two-component anti-Staphylococcus aureus lantibiotic activity produced by Staphylococcus aureus C55. Appl Environ Microbiol. 1998;64(12): 4803-8.

Nishie M, Shioya K, Nagao J, Jikuya H, Sonomoto K. ATP-dependent leader peptide cleavage by NukT, a bifunctional ABC transporter, during lantibiotic biosynthesis. J Biosci Bioeng. 2009 Dec;108(6):460-4.

Novick RP, Projan SJ, Kornblum J, Ross HF, Ji G, Kreiswirth B, et al. The agr P2 operon: an autocatalytic sensory transduction system in Staphylococcus aureus. Mol Gen Genet. 1995 Aug 30;248(4):446-58.

O'Connor EB, Cotter PD, O'Connor P, O'Sullivan $\mathrm{O}$, Tagg JR, Ross RP, et al. Relatedness between the two-component lantibiotics lacticin 3147 and staphylococcin C55 based on structure, genetics and biological activity. BMC Microbiol. 2007 Apr;7(1):24.

O'Sullivan JN, O'Connor PM, Rea MC, O'Sullivan O, Walsh CJ, Healy B, et al. Nisin J, a Novel Natural Nisin Variant, Is Produced by Staph- ylococcus capitis Sourced from the Human Skin Microbiota. J Bacteriol. 2020 Jan 15; 202(3):202.

O'Sullivan JN, Rea MC, O'Connor PM, Hill C, Ross RP. Human skin microbiota is a rich source of bacteriocin-producing staphylococci that kill human pathogens. FEMS Microbiol Ecol. 2018;95(2).

Olson ME, Todd DA, Schaeffer CR, Paharik AE, Van Dyke MJ, Büttner H, et al. Staphylococcus epidermidis agr quorum-sensing system: signal identification, cross talk, and importance in colonization. J Bacteriol. 2014 Oct; 196(19):3482-93.

Oman TJ, van der Donk WA. Follow the leader: the use of leader peptides to guide natural product biosynthesis. Nat Chem Biol. 2010 Jan;6(1):9-18.

Otto M. Staphylococcus aureus and Staphylococcus epidermidis peptide pheromones produced by the accessory gene regulator agr system. Peptides. 2001 Oct;22(10):1603-8.

Otto M. Staphylococci in the human microbiome: the role of host and interbacterial interactions. Curr Opin Microbiol. 2020 Feb;53:717.

Otto M, Süssmuth R, Vuong C, Jung G, Götz F. Inhibition of virulence factor expression in Staphylococcus aureus by the Staphylococcus epidermidis agr pheromone and derivatives. FEBS Lett. 1999 May;450(3):257-62.

Oves-Costales D, Kadi N, Challis GL. The longoverlooked enzymology of a nonribosomal peptide synthetase-independent pathway for virulence-conferring siderophore biosynthesis. Chem Commun (Camb). 2009 Nov 21(43):6530-41.

Pag U, Heidrich C, Bierbaum G, Sahl HG. Molecular analysis of expression of the lantibiotic pep5 immunity phenotype. Appl Environ Microbiol. 1999 Feb;65(2):591-8.

Paharik AE, Parlet CP, Chung N, Todd DA, Rodriguez EI, Van Dyke MJ, et al. CoagulaseNegative Staphylococcal Strain Prevents Staphylococcus aureus Colonization and Skin Infection by Blocking Quorum Sensing. Cell Host Microbe. 2017 Dec;22(6):746-e5.

Parlet CP, Brown MM, Horswill AR. Commensal Staphylococci Influence Staphylococcus aureus Skin Colonization and Disease. Trends Microbiol. 2019 Jun;27(6):497-507.

Parmeggiani A, Krab IM, Okamura S, Nielsen RC, Nyborg J, Nissen P. Structural basis of the action of pulvomycin and GE2270 A on elongation factor Tu. Biochemistry. 2006 Jun 6; 45(22):6846-57.

Peschel A, Augustin J, Kupke T, Stevanovic S, Götz F. Regulation of epidermin biosynthetic genes by EpiQ. Mol Microbiol. 1993;9(1):319.

Queck SY, Jameson-Lee M, Villaruz AE, Bach TH, Khan BA, Sturdevant DE, et al. RNAIIIIndependent Target Gene Control by the agr Quorum-Sensing System: Insight into the Evolution of Virulence Regulation in Staphylococcus aureus. Mol Cell. 2008 Oct;32(1): $150-8$. 
Rawls M, Ellis AK. The microbiome of the nose. Ann Allergy Asthma Immunol. 2019 Jan; 122(1):17-24.

Reisinger P, Seidel H, Tschesche H, Hammes WP. The effect of nisin on murein synthesis. Arch Microbiol. 1980 Oct;127(3):187-93.

Remy L, Carrière M, Derré-Bobillot A, Martini C, Sanguinetti M, Borezée-Durant E. The Staphylococcus aureus Opp1 ABC transporter imports nickel and cobalt in zinc-depleted conditions and contributes to virulence. Mol Microbiol. 2013;87(4):730-43.

Repka LM, Chekan JR, Nair SK, van der Donk WA. Mechanistic Understanding of Lanthipeptide Biosynthetic Enzymes. Chem Rev. 2017 Apr 26;117(8):5457-520.

Roy U, Islam MR, Nagao J, Iida H, Mahin AA, Li $\mathrm{M}$, et al. Bactericidal activity of nukacin ISK1 : an alternative mode of action. Biosci Biotechnol Biochem. 2014;78(7):1270-3.

Sahl HG, Brandis H. Production, purification and chemical properties of an antistaphylococcal agent produced by Staphylococcus epidermidis. J Gen Microbiol. 1981 Dec;127(2):37784.

Sashihara T, Kimura H, Higuchi T, Adachi A, Matsusaki H, Sonomoto K, et al. A Novel Lantibiotic, Nukacin ISK-1, of Staphylococcus warneri ISK-1: Cloning of the Structural Gene and Identification of the Structure. Biosci Biotechnol Biochem. 2000 Jan;64(11):24208.

Schilling NA, Berscheid A, Schumacher J, Saur JS, Konnerth MC, Wirtz SN, et al. Synthetic Lugdunin Analogues Reveal Essential Structural Motifs for Antimicrobial Action and Proton Translocation Capability. Angew Chem Int Ed Engl. 2019;58(27):9234-8.

Schnell N, Engelke G, Augustin J, Rosenstein R, Ungermann V, Götz F, et al. Analysis of genes involved in the biosynthesis of lantibiotic epidermin. Eur J Biochem. 1992 Feb 15;204(1): $57-68$.

Schnell N, Entian KD, Schneider U, Götz F, Zähner H, Kellner R, et al. Prepeptide sequence of epidermin, a ribosomally synthesized antibiotic with four sulphide-rings. Nature. 1988 May;333(6170):276-8.

Scott JC, Sahl HG, Carne A, Tagg JR. Lantibioticmediated anti-lactobacillus activity of a vaginal Staphylococcus aureus isolate. FEMS Microbiol Lett. 1992 May 15;72(1):97-102.

Shimafuji C, Noguchi M, Nishie M, Nagao J, Shioya $\mathrm{K}$, Zendo $\mathrm{T}$, et al. In vitro catalytic activity of $\mathrm{N}$-terminal and $\mathrm{C}$-terminal domains in NukM, the post-translational modification enzyme of nukacin ISK-1. J Biosci Bioeng. 2015 Dec;120(6):624-9.

Siezen RJ, Kuipers OP, de Vos WM. Comparison of lantibiotic gene clusters and encoded pro- teins. Antonie Van Leeuwenhoek. 1996 Feb; 69(2):171-84

Stachelhaus T, Mootz HD, Bergendahl V, Marahiel MA. Peptide bond formation in nonribosomal peptide biosynthesis. Catalytic role of the condensation domain. J Biol Chem. 1998 Aug 28;273(35):22773-81.

Stachelhaus T, Mootz HD, Marahiel MA. The specificity-conferring code of adenylation domains in nonribosomal peptide synthetases. Chem Biol. 1999 Aug;6(8):493-505.

$\mathrm{Su}$ TL. Micrococcin, an antibacterial substance formed by a strain of Micrococcus. Br J Exp Pathol. 1948 Oct;29(5):473-81.

Sun F, Cho H, Jeong DW, Li C, He C, Bae T. Aureusimines in Staphylococcus aureus are not involved in virulence. PLoS One. 2010 Dec 29; 5(12):e15703.

Thoendel M, Horswill AR. Identification of Staphylococcus aureus AgrD residues required for autoinducing peptide biosynthesis. J Biol Chem. 2009 Aug 14;284(33):21828-38.

Thoendel M, Kavanaugh JS, Flack CE, Horswill AR. Peptide signaling in the staphylococci. Chem Rev. 2011 Jan 12;111(1):117-51.

Todd DA, Parlet CP, Crosby HA, Malone CL, Heilmann KP, Horswill AR, et al. Signal Biosynthesis Inhibition with Ambuic Acid as a Strategy To Target Antibiotic-Resistant Infections. Antimicrob Agents Chemother. 2017;61(8):e00263-17.

van de Kamp M, Horstink LM, Van Den Hooven HW, Konings RN, Hilbers CW, Frey A, et al. Sequence Analysis by NMR Spectroscopy of the Peptide Lantibiotic Epilancin K7 from Staphylococcus epidermidis K7. Eur J Biochem. 1995a;227(3):757-71.

van de Kamp M, van den Hooven HW, Konings RN, Bierbaum G, Sahl HG, Kuipers OP, et al. Elucidation of the primary structure of the lantibiotic epilancin K7 from Staphylococcus epidermidis K7. Cloning and characterisation of the epilancin-K7-encoding gene and NMR analysis of mature epilancin K7. Eur J Biochem. 1995b Jun 1;230(2):587-600.

Varella Coelho ML, Santos Nascimento JD, Fagundes PC, Madureira DJ, Oliveira SS, Vasconcelos de Paiva Brito MA, et al. Activity of staphylococcal bacteriocins against Staphylococcus aureus and Streptococcus agalactiae involved in bovine mastitis. Res Microbiol. 2007 Sep;158(7):625-30.

Velásquez Juan E, Zhang X, van der Donk Wilfred A. Biosynthesis of the Antimicrobial Peptide Epilancin 15X and Its N-Terminal Lactate. Chem Biol. 2011 Jul;18(7):857-67.[not available]

Walter JD, Hunter M, Cobb M, Traeger G, Spiegel PC. Thiostrepton inhibits stable $70 \mathrm{~S}$ ribosome binding and ribosome-dependent GT-
Pase activation of elongation factor $\mathrm{G}$ and elongation factor 4. Nucleic Acids Res. 2012; 40(1):360-70.

Weil HP, Beck-Sickinger AG, Metzger J, Stevanovic S, Jung G, Josten $M$, et al. Biosynthesis of the lantibiotic Pep5. Isolation and characterization of a prepeptide containing dehydroamino acids. Eur J Biochem. 1990 Nov 26; 194(1):217-23.

Wieland Brown LC, Acker MG, Clardy J, Walsh CT, Fischbach MA. Thirteen posttranslational modifications convert a 14-residue peptide into the antibiotic thiocillin. Proc Natl Acad Sci USA. 2009;106(8):2549-53.

Wilaipun P, Zendo T, Okuda K, Nakayama J, Sonomoto $\mathrm{K}$. Identification of the nukacin KQU-131, a new type-A(II) lantibiotic produced by Staphylococcus hominis KQU-131 isolated from Thai fermented fish product (Pla-ra). Biosci Biotechnol Biochem. 2008 Aug;72(8):2232-5.

Williams MR, Costa SK, Zaramela LS, Khalil S, Todd DA, Winter HL, et al. Quorum sensing between bacterial species on the skin protects against epidermal injury in atopic dermatitis. Sci Transl Med. 2019 May 1;11(490): 11.

Wilson DJ, Shi C, Teitelbaum AM, Gulick AM, Aldrich CC. Characterization of AusA: a dimodular nonribosomal peptide synthetase responsible for the production of aureusimine pyrazinones. Biochemistry. 2013;52(5):92637.

Wladyka B, Wielebska K, Wloka M, Bochenska O, Dubin G, Dubin A, et al. Isolation, biochemical characterization, and cloning of a bacteriocin from the poultry-associated Staphylococcus aureus strain CH-91. Appl Microbiol Biotechnol. 2013 Aug;97(16):7229-39.

Wyatt MA, Wang W, Roux CM, Beasley FC, Heinrichs DE, Dunman PM, et al. Staphylococcus aureus nonribosomal peptide secondary metabolites regulate virulence. Science. 2010 Jul 16;329(5989):294-6.

Zhang L, Lin J, Ji G. Membrane anchoring of the AgrD N-terminal amphipathic region is required for its processing to produce a quorum-sensing pheromone in Staphylococcus aureus. J Biol Chem. 2004 May 7;279(19): 19448-56.

Zimmermann M, Fischbach MA. A Family of Pyrazinone Natural Products from a Conserved Nonribosomal Peptide Synthetase in Staphylococcus aureus. Chem Biol. 2010 Sep; 17(9):925-30.

Zipperer A, Konnerth MC, Laux C, Berscheid A, Janek D, Weidenmaier C, et al. Human commensals producing a novel antibiotic impair pathogen colonization. Nature. $2016 \mathrm{Jul}$; 535(7613):511-6. 